\title{
Green, yellow, red, or out of the blue? An assessment of Traffic Light Schemes to mitigate the impact of hydraulic fracturing-induced seismicity
}

\author{
James P. Verdon $(\mathbb{D} \cdot$ Julian J. Bommer
}

Received: 23 April 2020 / Accepted: 15 October 2020/Published online: 28 October 2020

(C) The Author(s) 2020

\begin{abstract}
Mitigating hydraulic fracturing-induced seismicity (HF-IS) poses a challenge for shale gas companies and regulators alike. The use of Traffic Light Schemes (TLSs) is the most common way by which the hazards associated with HF-IS are mitigated. In this study, we discuss the implicit risk mitigation objectives of TLSs and explain the advantages of magnitude as the fundamental parameter to characterise induced seismic hazard. We go on to investigate some of the key assumptions on which TLSs are based, namely that magnitudes evolve relatively gradually from green to yellow to red thresholds (as opposed to larger events occurring "out-of-the-blue"), and
\end{abstract}

\section{Highlights}

- We assess the evolution of magnitudes during sequences of hydraulic fracturing-induced earthquakes

- We find that the largest jumps and trailing magnitude increases are roughly 2 units

- A reasonable threshold for a Traffic Light Scheme should be set 2 units below the magnitude that is to be avoided

Supplementary Information The online version contains supplementary material available at https://doi.org/10.1007 /s10950-020-09966-9.

J. P. Verdon $(\bowtie)$

School of Earth Sciences, University of Bristol, Wills Memorial Building, Queen's Road, Bristol BS8 1RJ, UK

e-mail: James.Verdon@bristol.ac.uk

\section{J. J. Bommer}

Department of Civil and Environmental Engineering, Imperial College London, Skempton Building, South Kensington SW7

2AZ, UK

URL: https://orcid.org/0000-0002-9709-5223 that trailing event magnitudes do not increase substantially after injection stops. We compile HF-IS datasets from around the world, including the USA, Canada, the UK, and China, and track the temporal evolution of magnitudes in order to evaluate the extent to which magnitude jumps (i.e. sharp increases in magnitude from preceding events within a sequence) and trailing events occur. We find in the majority of cases magnitude jumps are less than 2 units. One quarter of cases experienced a post-injection magnitude increase, with the largest being 1.6. Trailing event increases generally occurred soon after injection, with most cases showing no increase in magnitude more than a few days after then end of injection. Hence, the effective operation of TLSs may require red-light thresholds to be set as much as two magnitude units below the threshold that the scheme is intended to avoid.

Keywords Induced seismicity · Traffic light schemes . Earthquake forecasting

\section{Introduction}

Hydraulic fracturing-induced seismicity (HF-IS) has become a significant concern for the unconventional gas industry (e.g. Schultz et al., 2020a). The seismicity response has been highly variable between different basins and regions. Many major plays, such as the Barnett (Texas), Bakken (North Dakota), and Marcellus (Pennsylvannia), have experienced little to no HF-IS despite thousands of wells being drilled and hydraulically stimulated (Verdon et al., 2016; van der Baan and Calixto, 
2017; Skoumal et al., 2018a). Conversely, some plays have experienced well-publicised cases of HF-IS.

In the West Canadian Sedimentary Basin (WCSB), stimulation of the Horn River, Duvernay and Montney Formations has produced several notable cases of HF-IS (Kao et al., 2018). The first cases of HF-IS in the WCSB were associated with the Horn River Shale in northeastern British Columbia between 2009 and 2011, where magnitudes reached M 3.8 (BC Oil and Gas Commission, 2012; Farahbod et al., 2015). The largest hydraulic fracturing induced events in the WCSB have occurred in the Montney and Duvernay Formations. The BC Oil and Gas Commission (2014) documented nearly 200 events with magnitudes ranging from $1.0<\mathrm{M}<4.4$ attributed to hydraulic fracturing of the Montney Shale from late 2013 to early 2014. Further cases of hydraulic fracturing induced seismicity in the Montney play have been recorded by Babaie Mahani et al. (2017) and Babaie Mahani et al. (2019); in both cases, the largest reported magnitudes were $M$ 4.6. Roth et al. (2020) and Peña-Castro et al. (2020) have provided a detailed analysis of events from the 2018 Septimus sequence.

The Fox Creek area, in which seismicity is induced by hydraulic fracturing of the Duvernay Formation, is probably one of the most extensively studied for induced seismicity anywhere in the world. Schultz et al. (2015a) and Bao and Eaton (2016) identified clusters of seismicity spatially and temporally correlated with stimulated wells. Continued activities in this area produced several events with $\mathrm{M}>4$ in 2015 and 2016 (Schultz et al., 2017). For the Fox Creek Duvernay cases of induced seismicity, high-resolution microseismic monitoring networks combined with $3 \mathrm{D}$ reflection seismic data have revealed in detail the interactions between hydraulic fractures, pre-existing natural fracture networks and faults (e.g. Eaton et al., 2018; Verdon et al., 2019; Eyre et al., 2019). While HF-IS in the Duvernay had previously been observed in the Fox Creek area, Schultz and Wang (2020) have identified several sequences of HF-IS from stimulation of the Duvernay near to the town of Red Deer, the largest of which had a magnitude of M 4.2.

In the Sichuan Basin, China, hydraulic fracturing for shale gas has produced $M>4$ events from 2014 onwards (Meng et al., 2019), and several events have exceeded M > 5, including an M 5.7 event in December 2018, followed by an M 5.3 in January 2019 (Lei et al., 2019a), and an M 6 earthquake in June 2019 (Liu and Zahradník, 2020), which produced several $M>5$ aftershocks. The M 5.7 December 2018 event was reported to have injured 17 people and caused extensive damage to roughly 400 houses (Lei et al., 2019a), while the M 6 event in June 2019 is reported to have killed 13 people, injured over 200 people, and damaged a large number of buildings (Yi et al., 2019). However, the causative factor for the June 2019 M 6 event is unclear, with several water injection wells associated with salt mining also found in close proximity to the epicentre (Lei et al., 2019b; Jia et al., 2020).

In the mid-continental USA, disentangling the signal of HF-IS from events caused by wastewater disposal has also proved challenging at times (e.g. Yoon et al., 2017). The first reported case of HF-IS identified in the USA occurred in the Woodford Shale, Oklahoma (Holland, 2013). Induced seismicity in Oklahoma has been dominated by disposal of produced fluids from conventional hydrocarbon operations (Rubenstein and Babaie Mahani, 2015), with the largest magnitude events associated with such activities (e.g. Keranan et al., 2013; Yeck et al., 2017). Nonetheless, Darold et al. (2014) reported a second case of HF-IS in Carter County, southern Oklahoma, and more recently, a re-analysis of earthquake catalogues by Skoumal et al. (2018b) identified 274 hydraulic fracturing wells, primarily in the Anadarko Basin, that correlate spatially and temporally with sequences of seismicity, with over 700 events with $\mathrm{M}>2$, and 12 events with magnitudes between $M$ 3.0-M 3.5.

The largest earthquake in the USA to have been linked to hydraulic fracturing occurred in the Eagle Ford Shale, southwest Texas. Fasola et al. (2019) identified 94 earthquakes with $M>2.0$ that could be correlated with hydraulic fracturing wells, with the largest having a magnitude of M 3.5 located near to Karnes City. While the primary cause of the Guy-Greenbrier sequence, where the largest event reached M 4.7, is believed to be high-volume wastewater disposal wells (Horton, 2012), Yoon et al. (2017) were able to identify clusters of events, with magnitudes below M 3, which appeared to be caused by nearby hydraulic fracturing activities in the Fayetteville Shale.

In the Appalachian Basin, hydraulic fracturing has predominantly taken place in the Marcellus Shale, which has been observed to be almost entirely aseismic (van der Baan and Calixto, 2017; Skoumal et al., 2018a). In contrast, hydraulic fracturing in the deeper Utica Shale has produced several cases of HF-IS, including an M 2.1 event in Harrison County, Ohio in 
October 2013 (Friberg et al., 2014), and an M 3.0 event in Mahoning County, Ohio, in March 2014 (Skoumal et al., 2015). Skoumal et al. (2018a) argue that the different responses between the Marcellus and Utica formations are produced by their differing depths, with the Utica Formation being much closer to the underlying basement. Again, cases of HF-IS may overlap with cases of wastewater disposal-induced seismicity (e.g. Kim, 2013).

In the UK, hydraulic fracturing of the Preese Hall well in 2011 generated an M 2.3 event: this was the first widely reported case of HF-IS (Clarke et al., 2014). In December 2018, stimulation of the Preston New Road PNR-1 well produced an M 1.5 event that was felt by nearby residents (Clarke et al., 2019), while stimulation of the adjacent PNR-2 well in August 2019 produced an M 2.9 event that was felt in the nearby towns of Blackpool and Preston (Kettlety et al. 2020; Cremen et al., 2020). While the magnitudes of events in the UK have not been as large as those in the WCSB or the Sichuan Basin, all 3 stimulated wells in the Bowland Shale have produced HF-IS of sufficient magnitude to be felt by nearby residents, although it should be noted that these three wells are within $5 \mathrm{~km}$ of each other, and so may not be representative of the Bowland as a whole. The UK government imposed an 18-month moratorium on shale gas hydraulic fracturing after the 2011 event and has reimposed a moratorium following the August 2019 event, significantly hampering the development of this industry.

The concept of a Traffic Light Scheme (TLS) to mitigate induced seismicity was first developed by Bommer et al. (2006) for application to an enhanced geothermal project in El Salvador. To date, TLSs have been the primary means by which HF-IS has been regulated and they have been generally recommended as an appropriate tool for this purpose for HF-IS as well as induced seismicity due to several other injectionrelated activities (NRC, 2012; Majer et al., 2012; Zoback, 2012). TLSs have the advantage of being conceptually simple, easy to explain to non-expert stakeholders and the general public, and relatively immune to model-based assumptions or parameterisation.

Given an expectation that TLSs will continue to play a role in regulation and mitigation of HF-IS, in this study we examine the key assumptions that underpin the successful operation of TLSs, and the extent to which they are met by cases of HF-IS. Before doing so, we begin by examining the potential hazard and risk posed by HF-IS, since any attempt to mitigate a hazard must start with a reasonable appreciation of the risk it poses. We follow this by an analysis of cases of HF-IS, spreading our net as widely as possible to capture examples of HF-IS from different plays and basins around the globe, focussing on the temporal evolution of event magnitudes, and the extent to which TLSs did, or could have, mitigated the occurrence of seismicity.

Although we focus on HF-IS in the paper, the same approach and many of our conclusions could be extended to other injection-based operations, including wastewater injection, enhanced geothermal systems and carbon capture and storage.

\section{TLSs as seismic risk mitigation tools}

TLSs have been very widely adopted and applied to the management of induced seismicity related to processes involving fluid injection. The objective of a TLS in such operations, whether explicitly stated or not, is to mitigate the potential seismic risk associated with induced earthquakes. Seismic risk can be defined as the possibility of undesirable consequences of earthquake effects on people and on the built environment (although serious consequences for a population are generally a direct result of damage to buildings). Conceptually, seismic risk is the product of four factors: the seismic hazard, which is the quantification of the earthquake effect, primarily ground shaking but also fault rupture, landslides and liquefaction; the exposure, which refers to the elements of the built environment in the locations where the shaking could happen; the fragility, which defines the likelihood of different degrees of damage being experienced under different levels of shaking; and the consequences of the building damage, which can be measured in economic terms, loss of function, or injury to inhabitants. When fragility and consequences are directly combined in a single function, it is referred to as vulnerability.

In conventional earthquake engineering for natural seismicity, the starting point is usually to characterise the seismic hazard and then to apply this to the structural design of new buildings or retrofit of existing buildings to reduce fragility in order to achieve tolerable risk goals. The approach to induced seismicity has generally been the opposite, namely to assess the vulnerability of the area surrounding the industrial activity that could potentially cause induced seismicity and then to apply controls to operations in order to maintain the hazard 
below thresholds that will result in acceptable or tolerable risk levels. In many cases, some of these steps have been implicit rather than explicit, but the focus has been clearly placed on mitigating risk through control of hazard, an option that is not available when dealing with natural earthquakes (other than by relocation, which in effect is the removal of the exposure). Bommer et al. (2015) have proposed that conventional earthquake engineering approaches could be invoked in the mitigation of induced seismic risk rather than relying exclusively on mechanisms for controlling the hazard, especially since the latter could pose a threat to the viability of the industrial activities in question. This concept was applied to conventional gas production in the Groningen gas field in the Netherlands through the development of an induced seismic risk model that is capable of estimating the risk impact both of changes in production and structural upgrading of the most susceptible buildings (van Elk et al., 2019). However, the viability of such an approach depends on whether the economic benefits of the operation warrant the investment in building strengthening. For many operations, including most hydraulic fracturing wells for oil and gas recovery, it will often be the case that the only option will be to mitigate risk through the design and implementation of an appropriate TLS.

Descriptions of TLSs for induced seismicity have often focussed on the monitoring systems and the response protocols when different thresholds are passed, and even more advanced concepts such as systems that adapt to the observed seismicity (e.g. Mena et al., 2013). All of these considerations are very important, but the actual risk goals of the TLS are often not stated explicitly. From the perspective of risk mitigation, the design of a TLS should consider three questions:

1. What is the risk target in terms of consequences to be avoided?

2. Which hazard metric is the best indicator of the risk potential?

3. What threshold of the hazard metric will ensure risk targets are not exceeded?

The risk could be considered in terms of disturbance to the population from felt shaking episodes. Such an approach was considered by Douglas and Aochi (2014), who defined risk in terms of the probability of induced events due to an enhanced geothermal system generating felt levels of shaking. Such a framework does not seem to have been used widely in practice although there is precedent for control of vibrations of anthropogenic origin in terms of limiting the disturbance to the exposed population. For example, the British Standards guidelines on tolerable levels of blast-induced vibrations (BSI, 2008) specify diurnal and nocturnal levels that apply for up to three blasts per day. These standards also relate the tolerable level of shaking to the frequency of shaking episodes: a factor is defined to reduce the tolerable levels when the number of events is greater than 3 , such that there is $25 \%$ reduction for 5 blasts per day, and almost a $50 \%$ decrease for 10 blasts. However, a TLS based on perceptible levels of shaking could be considered excessively conservative given that ground motions are typically felt at amplitudes far below those that might potentially cause damage. Moreover, there are strategies for dealing with felt shaking episodes, including communication-before and after such occasions - with the local population, which can be employed to avoid interruption of operations on this basis.

The risk targets are more likely, and more usefully, to be set in terms of avoiding damage to exposed buildings. A brief review of a few well-documented cases of risk considerations in the design of TLS can provide some useful insights into responses to the three questions posed above (although the specific thresholds are of less interest to the present discussion). In the design of the TLS developed by Bommer et al. (2006) for an enhanced geothermal system at Berlín, El Salvador, consideration was given to published guidelines on tolerable levels of anthropogenic vibrations, correlations between groundmotion amplitudes and intensity, and the fragility of the most vulnerable local buildings, which were constructed from adobe, to infer thresholds in terms of peak ground velocity (PGV). Although the amber and red thresholds of the TLS were defined in terms of PGV, the system was calibrated in terms of magnitude, based on the size of the earthquake at the injection depth required to generate median values of PGV matching these thresholds at the epicentre. The magnitudes were calibrated using a ground-motion prediction equation (GMPE) based on recordings from small-magnitude shallow seismic events recorded in the region (and updated during the operation using recordings of the induced seismicity). The original intention was to take account of the number of induced events and possible cumulative impacts on the local building stock by defining a decay of the PGV thresholds with increasing values of the cumulative Arias intensity 
(integral of the squared acceleration) from recorded motions. The decay rate was to have been calibrated against observations and recordings from seismic swarms in the same region, but the constraint was found to be insufficient. The alternative approach adopted was to superimpose the thresholds on a Gutenberg and Richter (1944) (G-R hereafter) recurrence plot, with the sloping boundary between the green and amber zones determined by the natural seismicity rates in the area for a 30-day period (the planned period of injection).

The Berlín TLS approach was subsequently adapted for the Basel Deep Heat Mining geothermal project in Switzerland (Häring et al., 2008). The risk targets were not explicitly stated but four levels (green, yellow, orange, and red) were defined for the TLS, each characterised by a threshold of local magnitude and a PGV value; it was not stated if both or either one needed to be exceeded to trigger the TLS level. The PGV thresholds were set to very low levels compared to those adopted by Bommer et al. (2006), suggesting that the implicit risk goals were rather conservative.

Westaway and Younger (2014) proposed the adoption of nuisance levels of PGV as the basis for controlling HF-induced ground vibrations in the UK, the thresholds being adopted from a variety of sources, including correlations between PGV and intensity and guidelines for the control of vibrations of anthropogenic origin. These authors discuss both empirical and stochastic GMPEs as tools for relating the PGV thresholds to magnitude but opt instead for a purely theoretical relationship between seismic moment, corner frequency and particle velocity.

Ader et al. (2019) discussed the design of a TLS for a deep geothermal project in Helsinki, highlighting some of the challenges in responding to the question of the best hazard indicator for the risk potential of induced seismic events. The design began by defining PGV levels such that green would correspond to motions that are not felt, amber to amplitudes of motion that might be felt but not cause damage, and the red light corresponding to the threshold level of PGV for cosmetic damage. Ader et al. (2019) identified two potential problems with using a PGV criterion for triggering different levels of the TLS. Firstly, false positives may arise due to ground vibrations from other sources, and secondly, false negatives may arise if the highest PGV should occur at a location other than where seismic instruments are installed to monitor the shaking. To address these potential pitfalls, Ader et al. (2019) proposed two sets of criteria for triggering of the amber level of the TLS: either the exceedance of the PGV threshold $(1 \mathrm{~mm} / \mathrm{s})$ at any sensor in association with an event of at least $M_{L} 1.0$, or an event of $M_{L} \geq 1.2$. The red light was triggered simply by an event of $\mathrm{M}_{\mathrm{L}} \geq 2.1$. The magnitude levels were determined using GMPEs for PGV but considering exceedance probabilities other than the 50-percentile (medians). One other innovative feature of the Helsinki TLS that is worthy of note was the identification of vibration-sensitive receptors in the region surrounding the injection well, which included a hospital and some research laboratories. Site-specific thresholds were established for these facilities, sometimes in terms of peak ground acceleration (PGA) rather than PGV, and these were maintained when found to be more conservative than the generic thresholds adopted for the TLS.

Schultz et al. (2020b) extended these concepts to a fully probabilistic risk framework for the design of a TLS to be deployed for hydraulic fracturing. They noted the merits of ground-motion amplitudes being more closely related to earthquake impact than magnitude, but also acknowledged that reliably monitoring the former is more challenging. Therefore, in common with earlier examples, they set thresholds in terms of PGV but then translated them into magnitudes. In this case, however, their conversion accounts for the depths of events, the separation between the injection wells and exposed buildings, and variability in the thresholds for nuisance and damage (i.e. fragility functions). Schultz et al. (2020b) proposed that red lights should be set at the level corresponding to shaking that is considered a nuisance, since this will provide a margin against motions that are potentially damaging. Once the red-light threshold has been established, they proposed that the amber light should be set two magnitude units lower.

It is therefore clear that a key issue is whether to use ground-motion amplitudes or earthquake magnitude as the hazard metric used to define TLS thresholds. The impact of an earthquake on a building or infrastructure facility depends on the severity of the ground shaking at the site of that facility. This observation would lead one to conclude that a ground-motion parameter is a preferable basis for fixing the thresholds of an effective TLS instead of using the earthquake magnitude. PGV has been frequently chosen as the ideal ground-motion parameter because it is widely used to define vibration limits, both for human perception and damage control, and it is generally considered to be a better indicator of 
the damage potential of earthquake shaking than PGA (Bommer and Alarcón, 2006). However, there are challenges in using PGV, some of which have been noted above. From an operational perspective, the main challenge is determining where and how PGV levels should be monitored, especially in view of the appreciable spatially variability observed in ground-motion fields generated by earthquakes. Instruments may be placed in close proximity to the injection well (where noise may be an issue), close to the nearest or most vulnerable buildings, or where surface ground conditions are most likely to lead to amplification of the shaking. Without a dense network of ground-motion instruments, it must be acknowledged that the largest PGV may not be recorded. Reliance on a critically-located instrument can make a PGV-based TLS susceptible should that specific instrument malfunction. Another important factor is that no single ground-motion parameter can be considered as a very reliable indicator of the damage potential of the ground motion. Exceeding a given threshold of PGV, for example, may be a necessary condition for a damaging motion, but it is not sufficient. This was demonstrated in the Berlín geothermal project for which the first TLS was developed: a magnitude $M_{L} 4.4$ earthquake (which occurred after pumping had been shut in) caused ground shaking that was registered with a PGA on the order of $0.8 \mathrm{~g}$ and a PGV value that exceeded the red-light threshold of the TLS, but no damage at all was reported (Bommer et al., 2006). Large amplitudes of PGA and PGV from small-magnitude earthquakes have been recognised for some time (e.g. Hanks and Johnson, 1976). However, it has also been recognised that these short-lived peaks will often contain insufficient energy to pose any threat in terms of structural damage. Indeed, the reasoning behind the imposition of a minimum magnitude in probabilistic seismic hazard analysis (PSHA) is to avoid inflating the hazard estimates with such peaks that do not contribute to risk (Bommer and Crowley, 2017). The degree of damage caused by earthquake ground shaking will ultimately depend on several factors, depending on the characteristics of the specific structure in question, including the frequency content of motion as well as the duration and energy content. A more effective way to capture the real damage potential of induced ground shaking could be through the use of a vector of ground-motion parameters but such an approach would not avoid the operational challenges associated with amplitude-based thresholds.
If the risk-based thresholds are to be calibrated to the specific conditions of an HF operation, appropriate magnitude levels can be inferred from the depth of the injection wells and reasonable assumptions regarding the separation of induced seismicity from the wells, together with the locations and characteristics of the exposed elements and the local ground conditions (provided a suitable GMPE can be adopted or developed). All of the relevant ground-motion characteristics can be estimated from the magnitude, depth, distance, and site conditions. From this perspective, if thresholds are to be defined in terms of an individual parameter, then given that in any particular application the approximate depth and location of induced earthquakes can be estimated a priori, magnitude may be the optimal parameter for a TLS. Notwithstanding the challenges of quantifying seismic event magnitudes accurately (e.g. Butcher et al., 2017; Kendall et al., 2019), magnitude is a parameter that can be calculated rapidly after an event, and this holds even if an individual instrument in the monitoring network fails to operate. If operations are monitored by regional networks, as opposed to dedicated site-specific arrays, which will often be the case if large numbers of hydraulic stimulations are taking place across a region, the magnitudes of larger events will be the best-constrained datum available, since locations may be poorly constrained and smaller events may be below the detection threshold. An optimal system may be based on magnitude thresholds for rapid calculation and response, with ground-motion thresholds, including but not necessarily limited to PGV, used to make decisions regarding resumption of full operations following an amber- or red-light trigger.

There are several options for calibration of magnitude thresholds, which could be based on locationspecific risk modelling or else from appropriate PGV thresholds, as was done in several of the case studies reviewed above. Another approach is to make inferences from global observations regarding the impacts of small-to-moderate magnitude earthquakes. Several studies have inferred that epicentral ground motions from induced and tectonic earthquakes of the same magnitude are comparable (e.g. Atkinson, 2020), the shallower depths that result in shorter travel paths for induced earthquakes being offset by lower stress drops (Hough, 2014; Atkinson et al., 2018).

This being the case, global observations of earthquake damage (e.g. Nievas et al., 2020a) can provide a basis for calibrating magnitude thresholds, provided 
certain assumptions are made regarding the completeness of reporting for damaging events (Nievas et al. $2020 \mathrm{~b}$ ) and that the exposed building stock is analogous to that affected by the earthquakes for which damage was reported. However, a critical question is whether the red-light threshold of a TLS should be fixed at the target risk level, or whether it is necessary to set the red light at a lower threshold if the risk target is to be achieved.

\section{Assumptions underpinning Traffic Light Schemes}

TLSs thresholds are typically assigned as "green", where operations proceed as normal, "yellow" or "amber", where operations proceed with caution, and "red", where injection is stopped, although additional threshold levels have been used (e.g. Häring et al., 2008). TLS thresholds have varied significantly between different jurisdictions (e.g. Kendall et al., 2019): in the UK the red-light threshold was M 0.5 (Clarke et al., 2019), whereas in Fox Creek area of the WCSB it is M 4.0 (Kao et al., 2018). Within Alberta, the regulator has also imposed red-light thresholds of M 2.5 in the vicinity of the Brazeau Dam, and M 3.0 near to the town of Red Deer. Other thresholds for HF-IS include Illinois, M 4; Oklahoma, M3.5; California, M 2.7; and Ohio, M 1.0.

Unlike the statistical modelling approaches demonstrated by, for example Kwiatek et al. (2019) and Clarke et al. (2019), TLSs are retroactive, with actions being taken after a threshold is reached. As such, the effectiveness of TLSs depends primarily on two assumptions. Firstly, TLSs presume the levels of seismicity will increase gradually during operations, triggering the yellow and then the red-light thresholds, allowing mitigation actions to be taken as these thresholds are reached. The alternative to this case is if large events occur "out of the blue" without precursory, smaller-magnitude seismicity, and therefore no mitigation would have been taken prior to a potentially damaging event.

Secondly, TLSs presume that mitigation actions (e.g. reducing or stopping injection) are effective in preventing further seismicity from occurring. Typically, rates of seismicity are observed to decrease once injection ceases (e.g. Clarke et al., 2019). However, while rates do decrease, seismicity does not stop instantaneously. Moreover, in many cases, the post-injection seismicity has continued to increase in magnitude (e.g. Majer et al., 2007; Häring et al., 2008; Clarke et al., 2014, 2019; Bao and Eaton, 2016; Kao et al., 2018;
Ellsworth et al., 2019; Cremen et al., 2020; Kettlety et al., 2020). Such earthquakes are often referred to as "trailing events".

The occurrence of magnitude "jumps" (where the next event to occur is significantly larger than any previous events during a sequence) and of trailing events poses challenges to the effectiveness of TLSs (e.g. Baisch et al., 2019). If the objective of a TLS is to preclude any events reaching a proscribed magnitude, then the red-light threshold must be set below this level, by an amount that is determined by the extent to which magnitude jumps, and trailing event magnitude increases, are likely to occur. Therefore, in this study, we examine case histories of HF-IS sequences to characterise the magnitude jumps and trailing events that have occurred, and therefore whether the assumptions inherent to the successful operation of TLSs are met.

The data compiled here also provide an opportunity to examine the timescales of induced seismicity relative to injection, and in particular, for how long after injection ceases are magnitudes be able to increase. Hydraulic fracturing represents a relatively abrupt intervention in the subsurface, with a high intensity of deformation around the well, but of limited extent both spatially and temporally: where local monitoring arrays with low location uncertainties have been used, induced seismicity is typically observed to occur within $1 \mathrm{~km}$, and at most $2 \mathrm{~km}$, from the well (e.g. Eaton et al., 2018; Eyre et al., 2019; Clarke et al., 2019), and hydraulic fracturing of a well typically takes place over a few days or weeks, after which the perturbations caused by stimulation will rapidly dissipate. This contrasts with wastewater disposal, for example, where injection takes place over many years, and so one might expect the resulting perturbations to be similarly long-standing (e.g. Keranen et al., 2013; Langenbruch and Zoback, 2016). Therefore, from a conceptual perspective, we would expect a closer temporal relationship between the well stimulation and induced seismicity for hydraulic fracturing.

\section{HF-IS case histories}

In this study, we evaluate HF-IS from a range of case studies across the globe. Our primary focus is on cases of HF-IS where magnitudes exceeded M 4, since this is a level at which some degree of nonstructural damage might be expected in some building types: for example, Baird et al. (2020) propose this as a threshold for light- 
frame wood buildings. However, to broaden the global breadth of our analyses, we also include examples that did not reach this threshold. We only consider cases of seismicity induced by hydraulic fracturing for shale gas. The case studies we examine are listed in Table 1. Where available, data were taken from published catalogues. Where digital catalogues were not available (for 11 of the 35 cases), we derived data by digitising figures provided in the papers mentioned herein. As an aside, we note that the limited data availability in many cases of HF-IS continues to pose a barrier to the scientific study of this phenomenon by the academic community.

We note that the cases selected represent a biased sample because cases where high-magnitude events occur draw wider attention. Even in relatively seismogenic areas, the majority of wells do not produce induced seismicity of sufficient magnitude to be detected, or produce relatively small events that do not attract the attention of regulators, the public, or academics, and therefore tend not to appear in publications. In such "well-behaved" examples, by definition magnitudes do not increase significantly, and hence there will be no significant magnitude jumps during operations or trailing magnitude increases after them.

\subsection{Western Canadian Sedimentary Basin}

The WCSB has experienced some of the highest levels of HF-IS, with several cases where magnitudes exceeded M 4. Kao et al. (2018) provided an overview of many of the largest magnitude HF-IS cases in the region, although where possible we add to these summaries with more detailed data provided by sitefocussed papers. Bao and Eaton (2016) documented six clusters of HF-IS associated with the Duvernay Formation in the vicinity of Crooked Lake, Alberta, between December 2014 to March 2015, where the largest magnitude reached M 4.4. Schultz et al. (2017) showed that seismicity has continued in this area, including an M 4.6 event in June 2015 and an M 4.5 event in January 2016 (also described by Wang et al., 2016). Eaton et al. (2018) described another site in the area that was monitored in detail using a dedicated microseismic monitoring array, providing a significant improvement in the detection threshold, and thereby our ability to image and understand the interaction between hydraulic fractures, pre-existing natural fractures, and faults (Verdon et al., 2019). The maximum magnitude at this site was M 3.2. Similar monitoring was used at a second site in the area, described by Eyre et al. (2019), at which an M 4.1 event occurred. More recently, Schultz and Wang (2020) have identified clusters of induced seismicity associated with stimulation of the Duvernay near to the city of Red Deer, from which we examine the two largest cases, with magnitudes of M 4.2 and M 3.1. For the cluster ESB10 described by Schultz and Wang (2020), we note that this sequence is adjacent to the ESB09 cluster, which was linked to a nearby well that had ceased stimulation only 4 days before the start of operations at the ESB10 well. However, we follow Schultz and Wang (2020) in treating these sequences as unrelated (note that the ESB09 cluster did not produce magnitudes significantly above M 2.0, and so is not included in our study). We also include the Cardston HF-IS sequence in southern Alberta, where an M 3.0 event was caused by stimulation of the Exshaw Formation (Schultz et al., 2015b).

For the Montney, we use the cases described by Kao et al. (2018) for the sequences in August 2014 and in July 2016, with maximum magnitudes of M 4.5 and M 3.9, respectively. To these, we add the HF-IS sequence from August 2015 described by Babaie Mahani et al. (2017), and the sequence near to Septimus described by PeñaCastro et al. (2020). We note that the largest event in this sequence is described as M 3.9 in the Composite Alberta Seismicity Catalog (Fereidoni and Cui, 2015), whereas Peña-Castro et al. (2020) assigned a moment magnitude of M 4.2. This discrepancy highlights the challenge of assigning accurate and consistent magnitudes to HF-IS sequences (Kendall et al., 2019). We also note that more detailed analysis of seismic data can reveal precursory events not identified in initial studies, as can be seen by a comparison between the event catalogues for the Septimus sequence reported by Babaie Mahani et al. (2019) and those of Peña-Castro et al. (2020) and Roth et al. (2020).

\subsection{Sichuan Basin, China}

Meng et al. (2019) documented the increase of HF-IS in the Sichuan Basin from 2014 onwards, but no single case studies are presented in sufficient detail for our analysis. Lei et al. (2017) documented increasing seismicity across the Sichuan Basin, and in particular, provided detailed 
Table 1 Case studies, including the observed maximum magnitude, the largest magnitude "jump", any trailing event magnitude increase, and the number of days after injection for a trailing event magnitude increase to occur

\begin{tabular}{|c|c|c|c|c|c|c|c|c|}
\hline & Site & Date & Region/formation & Reference & $M_{\text {MAX }}^{O}$ & $\begin{array}{l}\text { Max Mag } \\
\text { "Jump" }\end{array}$ & $\begin{array}{l}\text { Trailing } \\
\text { increase }\end{array}$ & $\begin{array}{l}\text { Days post-inj to } \\
\text { largest event }\end{array}$ \\
\hline 1 & Preese Hall & $\begin{array}{l}\text { April 1, } \\
2011\end{array}$ & UK/Bowland & $\begin{array}{l}\text { Clarke et al. } \\
\text { (2014) }\end{array}$ & 2.3 & 0.9 & 0.9 & $<1$ \\
\hline 2 & $\begin{array}{l}\text { Preston New } \\
\text { Road } 1\end{array}$ & $\begin{array}{l}\text { December } \\
11,2018\end{array}$ & UK/Bowland & $\begin{array}{l}\text { Clarke et al. } \\
\text { (2019) }\end{array}$ & 1.5 & 0.4 & 0.4 & $<1$ \\
\hline 3 & $\begin{array}{l}\text { Preston New } \\
\text { Road } 2\end{array}$ & $\begin{array}{l}\text { August 26, } \\
2019\end{array}$ & UK/Bowland & $\begin{array}{l}\text { Cremen et al. } \\
\text { (2020) }\end{array}$ & 2.9 & 0.8 & 1.3 & 3 \\
\hline 4 & Tony Creek & $\begin{array}{l}\text { November } \\
29,2016\end{array}$ & WCSB/Duvernay & $\begin{array}{l}\text { Eaton et al. } \\
\text { (2018) }\end{array}$ & 3.2 & 1.2 & 0 & \\
\hline 5 & Crooked Lake & $\begin{array}{c}\text { January } 12, \\
2016\end{array}$ & WCSB/Duvernay & Eyre et al. (2019) & 4.1 & 1.5 & 0 & \\
\hline 6 & $\begin{array}{l}\text { Crooked Lake } \\
\quad \text { C1 }\end{array}$ & $\begin{array}{c}\text { January } 23, \\
2015\end{array}$ & WCSB/Duvernay & $\begin{array}{l}\text { Bao \& Eaton } \\
\quad(2016)\end{array}$ & 3.9 & 1.1 & 0.7 & 15 \\
\hline 7 & $\begin{array}{l}\text { Crooked Lake } \\
\text { C2 }\end{array}$ & $\begin{array}{c}\text { January } 16, \\
2015\end{array}$ & WCSB/Duvernay & $\begin{array}{l}\text { Bao \& Eaton } \\
\quad(2016)\end{array}$ & 2.9 & 0.6 & 0 & \\
\hline 8 & $\begin{array}{l}\text { Crooked Lake } \\
\text { C3 }\end{array}$ & $\begin{array}{c}\text { January } 14, \\
2015\end{array}$ & WCSB/Duvernay & $\begin{array}{l}\text { Bao \& Eaton } \\
\text { (2016) }\end{array}$ & 3.7 & 0.7 & 0 & \\
\hline 9 & $\begin{array}{l}\text { Crooked Lake } \\
\quad \text { C4 }\end{array}$ & $\begin{array}{l}\text { March 7, } \\
2015\end{array}$ & WCSB/Duvernay & $\begin{array}{l}\text { Bao \& Eaton } \\
\quad(2016)\end{array}$ & 2.7 & 0.4 & 0 & \\
\hline 10 & $\begin{array}{l}\text { Crooked Lake } \\
\quad \text { C5 }\end{array}$ & $\begin{array}{c}\text { February } 8, \\
2015\end{array}$ & WCSB/Duvernay & $\begin{array}{l}\text { Bao \& Eaton } \\
\quad(2016)\end{array}$ & 2.9 & 0.6 & 0.1 & $<1$ \\
\hline 11 & $\begin{array}{l}\text { Crooked Lake } \\
\quad \text { C6 }\end{array}$ & $\begin{array}{l}\text { February } 10, \\
2015\end{array}$ & WCSB/Duvernay & $\begin{array}{l}\text { Bao \& Eaton } \\
\quad(2016)\end{array}$ & 3.0 & 0.6 & 0 & \\
\hline 12 & $\begin{array}{l}\text { Crooked Lake } \\
\quad \text { SS10 }\end{array}$ & $\begin{array}{c}\text { June } 13 \text {, } \\
2015\end{array}$ & WCSB/Duvernay & $\begin{array}{l}\text { Schultz et al. } \\
\text { (2017) }\end{array}$ & 4.0 & 1.6 & 1.6 & 7 \\
\hline 13 & $\begin{array}{r}\text { Red Deer } \\
\text { ESB02 }\end{array}$ & $\begin{array}{l}\text { March 9, } \\
2018\end{array}$ & WCSB/Duvernay & $\begin{array}{l}\text { Schultz \& Wang } \\
\quad(2020)\end{array}$ & 3.1 & 1.5 & 0 & \\
\hline 14 & $\begin{array}{l}\text { Red Deer } \\
\text { ESB09/10 }\end{array}$ & $\begin{array}{l}\text { March 4, } \\
2019\end{array}$ & WCSB/Duvernay & $\begin{array}{l}\text { Schultz \& Wang } \\
\quad(2020)\end{array}$ & 4.2 & $2.4^{\mathrm{b}}$ & 0 & \\
\hline 15 & Cardston & $\begin{array}{l}\text { December 4, } \\
2011\end{array}$ & WCSB/Exshaw & $\begin{array}{l}\text { Schultz et al. } \\
\text { (2015b) }\end{array}$ & 3.0 & 0.7 & 0 & \\
\hline 16 & Montney & $\begin{array}{l}\text { August 4, } \\
2014\end{array}$ & WSCB/Montney & Kao et al. (2018) & 4.5 & $>1.8^{\mathrm{c}}$ & 0 & \\
\hline 17 & Montney & $\begin{array}{l}\text { August 17, } \\
2015\end{array}$ & WCSB/Montney & $\begin{array}{c}\text { Babaie Mahani } \\
\text { et al. (2017) }\end{array}$ & 4.1 & 2.7 & 0 & \\
\hline 18 & Montney & $\begin{array}{l}\text { July } 12, \\
2016\end{array}$ & WCSB/Montney & Kao et al. (2018) & 3.9 & $\mathrm{NP}^{\mathrm{a}}$ & 0 & \\
\hline 19 & Septimus & $\begin{array}{l}\text { November } \\
30,2018\end{array}$ & WCSB/Montney & $\begin{array}{l}\text { Peña-Castro et al. } \\
\text { (2020) }\end{array}$ & 4.2 & 2.1 & 0 & \\
\hline 20 & Shangluo Y6-8 & $\begin{array}{l}\text { January 27, } \\
2017\end{array}$ & Sichuan, China & Lei et al. (2017) & 4.7 & 1.1 & 0 & \\
\hline 21 & Shangluo N4 & $\begin{array}{l}\text { April 9, } \\
2016\end{array}$ & Sichuan, China & Lei et al. (2017) & 3.0 & 0.5 & 0 & \\
\hline 22 & $\begin{array}{l}\text { Changning } \\
\text { N201 }\end{array}$ & $\begin{array}{l}\text { December } \\
16,2018\end{array}$ & Sichuan, China & Lei et al. (2019) & 5.8 & 2.1 & 0 & \\
\hline 23 & $\begin{array}{l}\text { Harrison } \\
\text { County }\end{array}$ & $\begin{array}{l}\text { October 4, } \\
2013\end{array}$ & Ohio/Utica & $\begin{array}{l}\text { Friberg et al. } \\
\quad(2014)\end{array}$ & 2.1 & 0.4 & 0 & \\
\hline 24 & $\begin{array}{l}\text { Mahoning } \\
\text { County }\end{array}$ & $\begin{array}{l}\text { March 10, } \\
2014\end{array}$ & Ohio/Utica & $\begin{array}{l}\text { Skoumal et al. } \\
\text { (2015) }\end{array}$ & 3.0 & 0.7 & 0 & \\
\hline 25 & Garvin County & $\begin{array}{c}\text { January } 18, \\
2011\end{array}$ & Oklahoma/Woodford & Holland (2013) & 2.9 & 0.4 & 0 & \\
\hline 26 & Carter County & July 7, 2014 & Oklahoma/Woodford & $\begin{array}{l}\text { Darold et al. } \\
\text { (2014) }\end{array}$ & 3.2 & NP & 0 & \\
\hline 27 & Karnes & May 1,2018 & Texas/Eagle Ford & & 3.5 & 1.1 & 0 & \\
\hline
\end{tabular}


Table 1 (continued)

\begin{tabular}{|c|c|c|c|c|c|c|c|c|}
\hline & Site & Date & Region/formation & Reference & $M_{\text {MAX }}^{O}$ & $\begin{array}{l}\text { Max Mag } \\
\text { "Jump" }\end{array}$ & $\begin{array}{l}\text { Trailing } \\
\text { increase }\end{array}$ & $\begin{array}{l}\text { Days post-inj to } \\
\text { largest event }\end{array}$ \\
\hline & & & & $\begin{array}{c}\text { Fasola et al. } \\
\text { (2019) }\end{array}$ & & & & \\
\hline 28 & $\begin{array}{l}\text { Guy-Greenbrier } \\
\text { C1 }\end{array}$ & $\begin{array}{l}\text { July } 23 \text {, } \\
2010\end{array}$ & Arkansas/Fayetteville & $\begin{array}{l}\text { Yoon et al. } \\
\text { (2017) }\end{array}$ & 2.4 & 0.9 & 0 & \\
\hline 29 & $\begin{array}{l}\text { Guy-Greenbrier } \\
\text { C2 }\end{array}$ & $\begin{array}{l}\text { August 21, } \\
2010\end{array}$ & Arkansas/Fayetteville & $\begin{array}{l}\text { Yoon et al. } \\
\text { (2017) }\end{array}$ & 1.8 & 0.5 & 0.7 & 23 \\
\hline 30 & $\begin{array}{l}\text { Guy-Greenbrier } \\
\text { C6 }\end{array}$ & July 7, 2010 & Arkansas/Fayetteville & $\begin{array}{l}\text { Yoon et al. } \\
\text { (2017) }\end{array}$ & 1.3 & 0.1 & 0 & \\
\hline 31 & $\begin{array}{l}\text { Guy-Greenbrier } \\
\text { C7 }\end{array}$ & $\begin{array}{l}\text { August 27, } \\
2010\end{array}$ & Arkansas/Fayetteville & $\begin{array}{l}\text { Yoon et al. } \\
\text { (2017) }\end{array}$ & 2.2 & 0.5 & 0 & \\
\hline 32 & $\begin{array}{l}\text { Guy-Greenbrier } \\
\text { C8 }\end{array}$ & $\begin{array}{l}\text { June } 10, \\
2010\end{array}$ & Arkansas/Fayetteville & $\begin{array}{l}\text { Yoon et al. } \\
\text { (2017) }\end{array}$ & 2.7 & 0.4 & 0.5 & 4 \\
\hline 33 & $\begin{array}{l}\text { Guy-Greenbrier } \\
\text { C10 }\end{array}$ & $\begin{array}{c}\text { July } 24, \\
2010\end{array}$ & Arkansas/Fayetteville & $\begin{array}{l}\text { Yoon et al. } \\
\text { (2017) }\end{array}$ & 1.7 & 0.4 & 0 & \\
\hline 34 & $\begin{array}{l}\text { Guy-Greenbrier } \\
\text { C11 }\end{array}$ & $\begin{array}{l}\text { August 9, } \\
2010\end{array}$ & Arkansas/Fayetteville & $\begin{array}{l}\text { Yoon et al. } \\
\text { (2017) }\end{array}$ & 2.0 & 0.5 & 0 & \\
\hline 35 & $\begin{array}{l}\text { Guy-Greenbrier } \\
\text { C13 }\end{array}$ & June 7, 2010 & Arkansas/Fayetteville & $\begin{array}{l}\text { Yoon et al. } \\
\text { (2017) }\end{array}$ & 2.9 & 0.6 & 1.1 & 3 \\
\hline
\end{tabular}

${ }^{\mathrm{a}} \mathrm{NP}=$ no precursory events prior to the largest event

${ }^{\mathrm{b}}$ Jump is 2.2 units if cluster ESB09 is included

${ }^{\mathrm{c}}$ This assumes that the minimum detection threshold is M 2, implying a jump of at least 1.8 to the M 3.8 event that occurred on 30 th July 2014

analysis of HF-IS that was associated with two pads: pad N4, which produced an M 3.0 event in April 2016, and pads Y6-8, which produced an M 4.7 event in January 2017. Lei et al. (2019) reported further HF-IS in the same region, focussing on pad N201, which produced an M 5.7 earthquake in December 2018. We note that caution may be required with these events, since recent studies have linked some of the induced seismicity that has occurred in the Sichuan Basin with salt mining processes rather than hydraulic fracturing (Lei et al., 2019b; Jia et al., 2020).

\subsection{Bowland Shale, UK}

To date, three wells have been hydraulic fractured in the Bowland Shale in northwest England. The first was the Preese Hall well in Lancashire in 2011, which produced an M 2.3 event (Clarke et al., 2014). In 2018, the Preston New Road PNR-1z well was stimulated, approximately $4 \mathrm{~km}$ from the Preese Hall site, producing an M 1.5 event (Clarke et al., 2019), and in 2019 the adjacent PNR-2 well was stimulated, producing an M 2.9 event (Cremen et al., 2020; Kettlety et al., 2020).

\subsection{United States}

In the mid-continental USA, we use the clusters of HFIS identified by Yoon et al. (2017) from stimulation of the Fayetteville Shale in Arkansas in 2010, where magnitudes reached M 2.9. To these, we add the 2011 sequence from Garvin County, OK, where magnitudes again reached M 2.9 (Holland, 2013); the 2014 sequence from Carter County, OK, where magnitudes reached M 3.2 (Darold et al. 2014), and the $2018 \mathrm{M}$ 3.5 sequence near to Karnes City, TX (Fasola et al., 2019). In the Appalachian Basin, we consider the 2013 Harrison County sequence identified by Friberg et al. (2014), and the Mahoning County sequence identified by Skoumal et al. (2015), both of which were associated with stimulation of the Utica Shale.

\section{Analyses of HF-IS sequences}

Table 1 lists the observed magnitudes, magnitude jumps, and trailing event increases for each of the cases described in Section 4. Figure 1 shows the temporal evolution for each of these sequences. 


\subsection{Magnitude jumps and trailing events}

Figure 2 shows a histogram and cumulative distribution of the observed magnitude jumps. We find that for $60 \%$ of cases studied, the largest jump in maximum event size was less than 1 magnitude unit, implying a relatively gradual evolution of event size during injection. In $23 \%$ of cases, there was a magnitude jump of between 1 and 2 magnitude units, while 4 cases $(11 \%)$ had a magnitude jump of more than 2 units. Similarly, one case in the Montney Shale (Babaie Mahani et al., 2017), and the Carter County, OK, case (Darold et al., 2014) did not appear to have any precursory events. However, we note that monitoring in both of these regions is provided only by regional networks rather than by dedicated local microseismic arrays (e.g. Eaton et al., 2018; Clarke et al., 2019), and we do not have detailed information about the detection thresholds (i.e. at what level precursory event might have occurred but was not detectable from the available arrays).

Figure 3 shows a histogram and cumulative distribution of the observed post-injection trailing magnitude increases. We find that $74 \%$ of cases showed no postinjection increase in magnitudes, $17 \%$ showed a postinjection magnitude increase of between 0 and 1 magnitude units, and $9 \%$ had an increase greater than 1 unit,

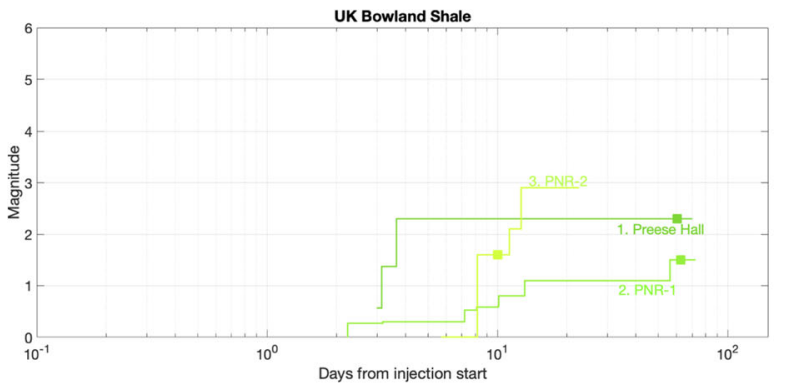

(a)

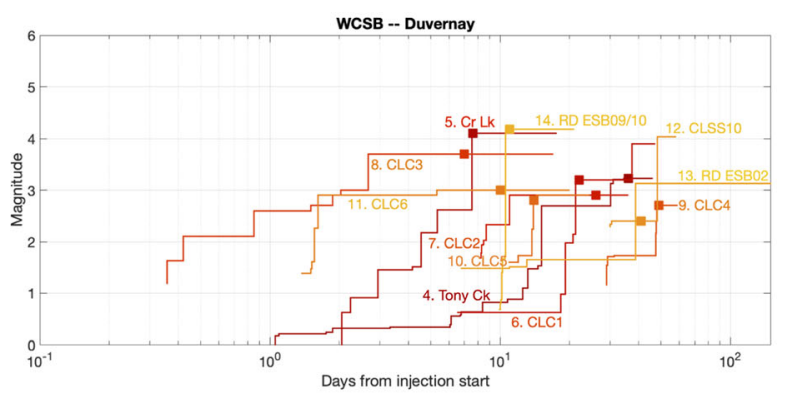

(b)

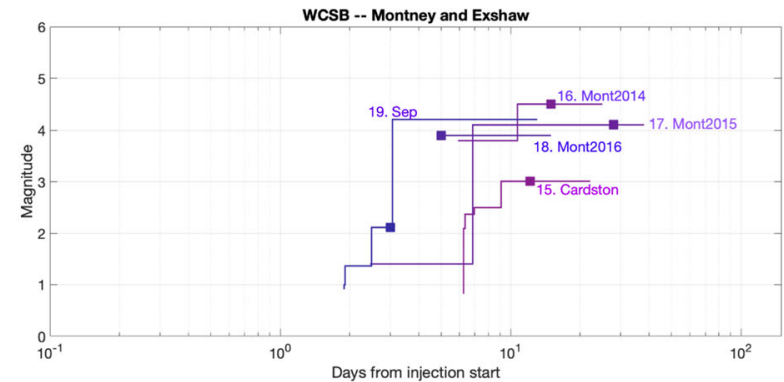

(c)

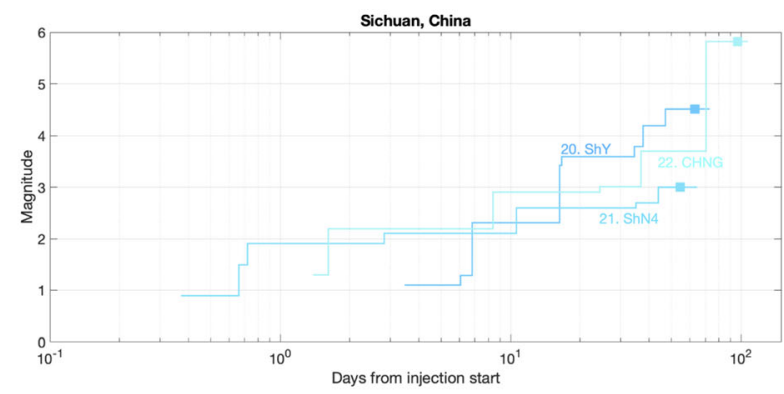

(d)

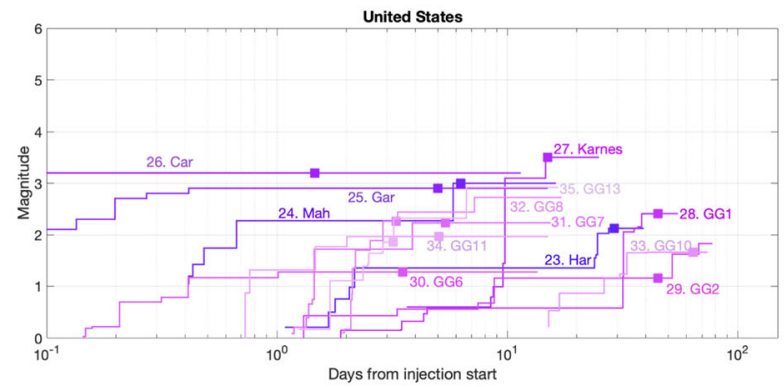

(e)

Fig. 1 Temporal evolution of maximum magnitudes for the HFIS sequences detailed in Table 1, relative to the start of injection. For ease of visibility, we divide the cases by region, showing a UK Bowland Shale, b WCSB Duvernay cases, $\mathbf{c}$ other WCSB cases, $\mathbf{d}$
Sichuan Basin, China, and e USA. Lines are labelled according to the case studies listed in Table 1. Coloured squares along each line denote the point at which injection stopped in each case 
Fig. 2 Histogram (bars) and cumulative percent (circles) of observed magnitude jumps for the cases listed in Table 1

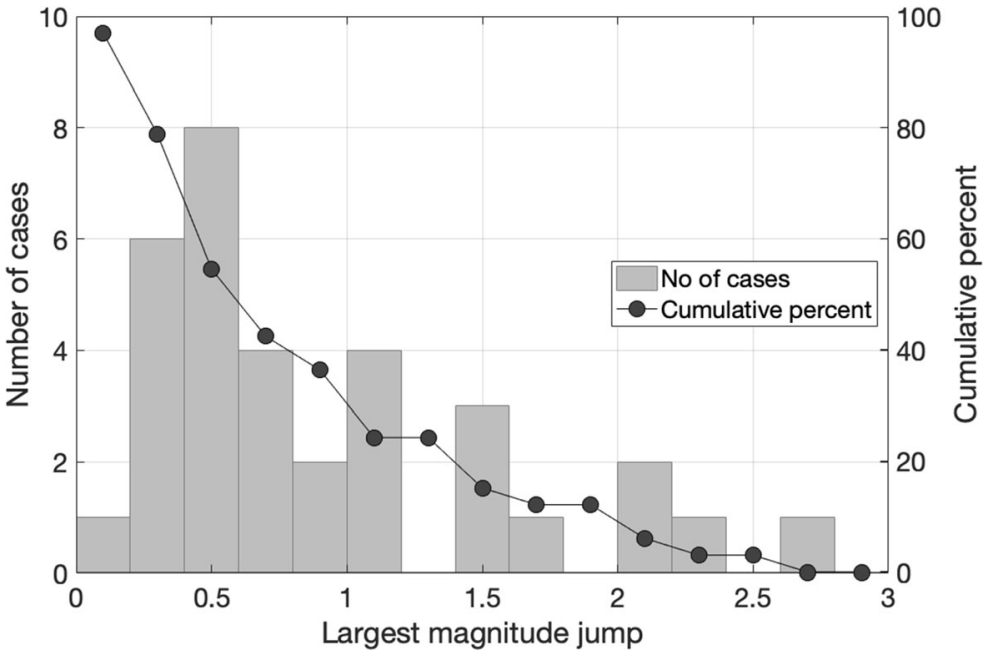

with the largest being a 1.6 magnitude unit increase at SS10 cluster of the Crooked Lake sequences described by Schultz et al. (2017).

Schultz et al. (2020b) used a statistical approach to estimate the likely size of post-injection trailing events using an assumption that $20 \%$ of events typically occur after injection. Given a G-R distribution with $b=1$, from the increased event count, Schultz et al. (2020b) estimated that the probabilities of trailing event magnitude increases being less than 1, 2, and 3 magnitude units were $90 \%, 99 \%$, and $99.9 \%$, respectively. We perform a similar analysis, albeit differing from Schultz et al. (2020b) in that we do not assume the occurrence of a red-light event. We use a stochastic approach, drawing populations of 1000 events from a G-R distribution with $b=1$, and then drawing an additional 200 events (i.e. an additional $20 \%$ of events occurring post-injection) from the same distribution, and comparing the maximum magnitudes from the two populations. The results are shown in Fig. 3 (dashed line): the probability of a trailing event magnitude increase is slightly below $20 \%$, and the probabilities of trailing increases of more than 1 and 2 magnitude units are $2 \%$ and $1 \%$, respectively. Our observed population has a slightly higher proportion of cases with a trailing event increase (26\%), possibly representing the bias described above that published cases of HF-IS are more likely to focus on the "badly-behaved" cases, or perhaps simply representing the uncertainties inherent in assuming that $20 \%$ of events occur after injection.
Fig. 3 Histogram (bars) and cumulative percent (circles) of observed magnitude jumps for the cases listed in Table 1. We also show the simulated magnitude increase based on the concept outlined by Schultz et al. (2020b) (dashed line)

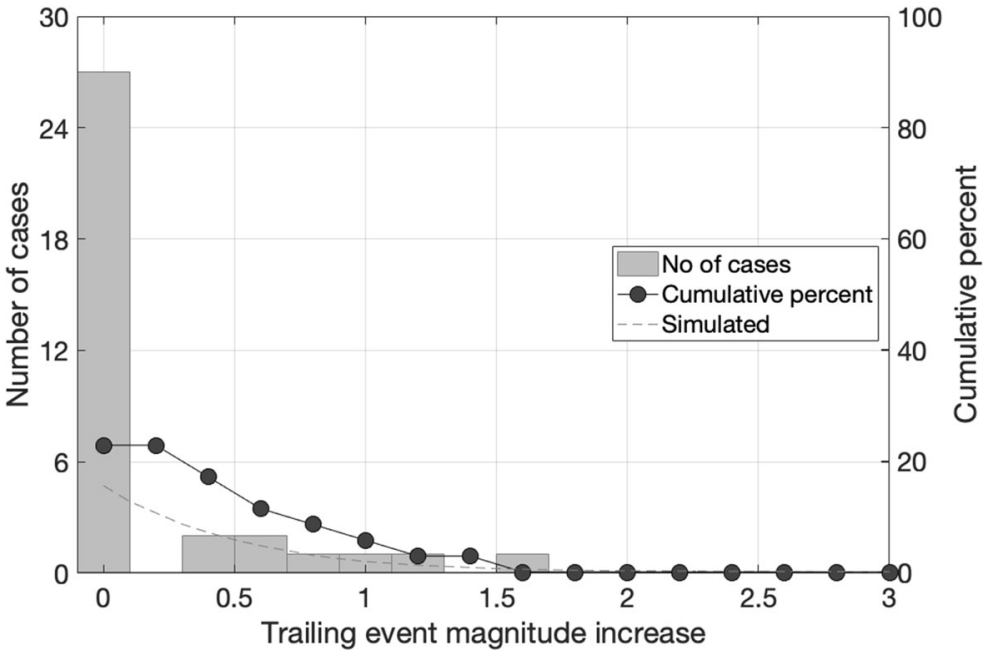


Fig. 4 Histogram (bars) and cumulative percent (circles) of observed times in which postinjection magnitude increases occur. Cases for which no postinjection increase occur are plotted at 0

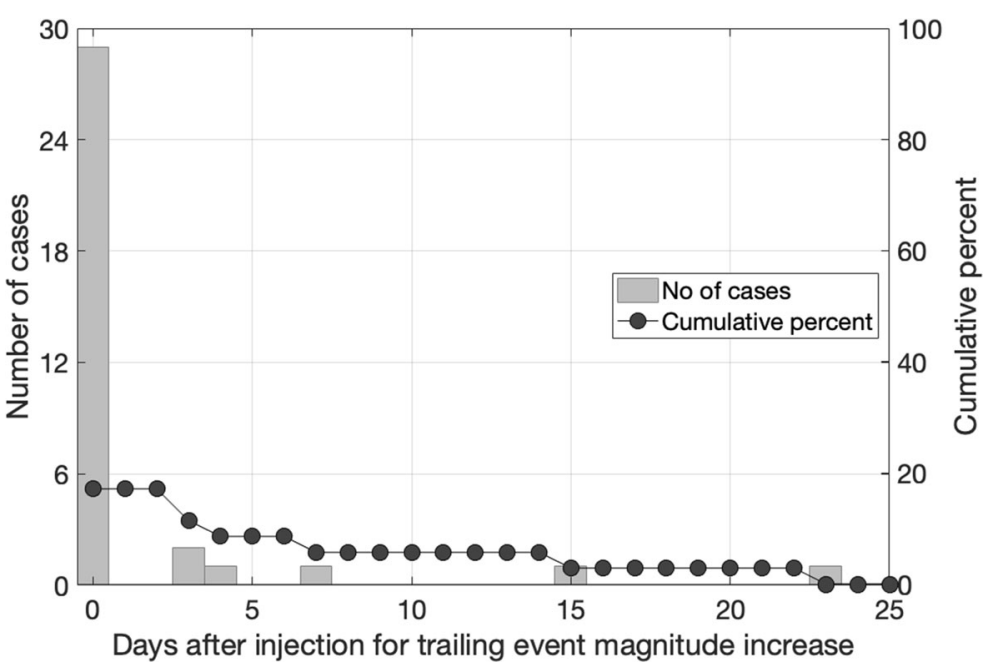

\subsection{Timescales for trailing events}

Table 1 also lists the number of days post-injection on which a trailing event magnitude increase occurred. Figure 1 also shows the post-injection evolution of seismicity for each case study. Figure 4 shows a histogram and cumulative distribution of the observed times in which post-injection trailing magnitude increases occur. As described above, for $74 \%$ of cases, the largest event occurred during stimulation, and therefore there was no trailing event magnitude increase. Hence, $26 \%$ of cases experienced increases in magnitude for post-injection trailing events. In $17 \%$ of cases, the largest event occurred within 3-4 days of stimulation, while in 9\% of cases the lag between injection and the largest event was greater than 1 week. The longest observed delay between injection and the occurrence of a larger event was 23 days. Note that these times define the window within which magnitudes continue to increase post-injection, it is not the time in which all seismicity associated with a HF-IS has ceased.

The observed time windows in which trailing events occur confirm our hypothesis with respect to the tight correlation between stimulation and induced seismicity: long lag times between stimulation and increases in seismic magnitude are not observed to occur. These observations characterise the time period for which an otherwise quiescent site may need to be monitored before it can be assumed that the risk of induced seismicity has passed. Moreover, they also define a suitable time window that might be used when performing datamining exercises to identify potential HF-IS candidates (e.g. Atkinson et al., 2016).
The compiled datasets also allow us to investigate the timing of the largest event within each sequence. Van der Elst et al. (2016) argued that the timing of the largest event within a sequence will be random, since the occurrence of seismicity should be controlled entirely by tectonic processes. In their cases studies, which included induced seismicity from a variety of industrial activities, van der Elst et al. (2016) did not find evidence to rule out the random occurrence of the largest events within the sequence. If true, this would pose a challenge for TLSs, since it implies that a large event could be the first to occur (or may occur relatively early in the sequence) and that magnitudes are controlled solely by tectonic factors. In contrast, Skoumal et al. (2018b) examined sequences of HF-IS in Oklahoma and found a statistically significant trend $(p=2.5 \%)$ for the largest events to occur in the latter half of their sequences and for the largest events to occur towards the end of injection periods.

We performed this analysis for the 24 cases where we had access to full event catalogues. Figure 5 shows the number of events prior to the largest event, as a percentage of the total number of events, $N_{\text {prior }} / N_{\text {total }}$, for each case. We find that for 17 of the 24 cases examined the largest event occurred in the latter part of the sequence, indicating that the occurrence of the largest event is not randomly distributed, with $p=4 \%$. Moreover, we note that the cases where large events occurred early within sequences were all cases with relatively small numbers of events in the overall catalogue, which may indicate an impact of detection limitations failing to identify precursory events that are reduced when larger catalogues are produced by better monitoring systems, or by more detailed analysis of 
recorded data using more advanced event detection algorithms (e.g. Verdon et al., 2017). This impact can be understood by comparing the report of the Montney Septimus sequence made by Babaie Mahani et al. (2019), which did not identify any precursory events, and the catalogues produced by re-analysis of the data by PeñaCastro et al. (2020) and Roth et al. (2020).

Our results therefore are in agreement with the results found by Skoumal et al. (2018b), indicating that the largest events are unlikely to occur at an early point within HF-IS sequences, but instead, magnitudes tend to increase as injection progresses.

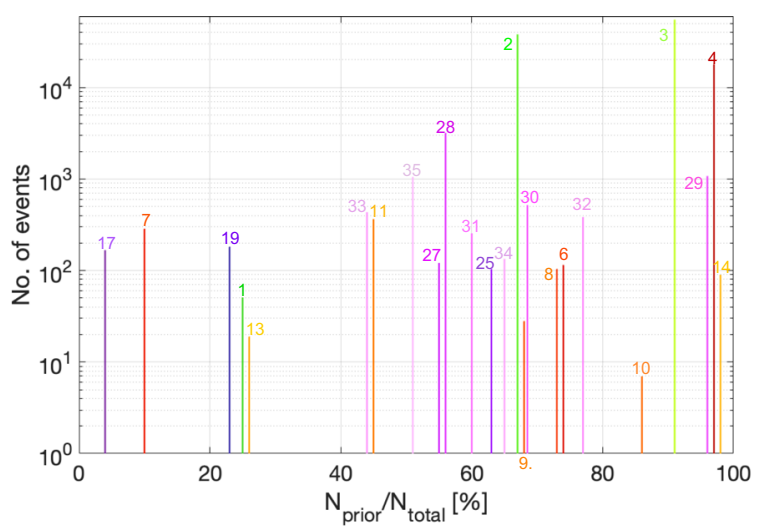

(a)

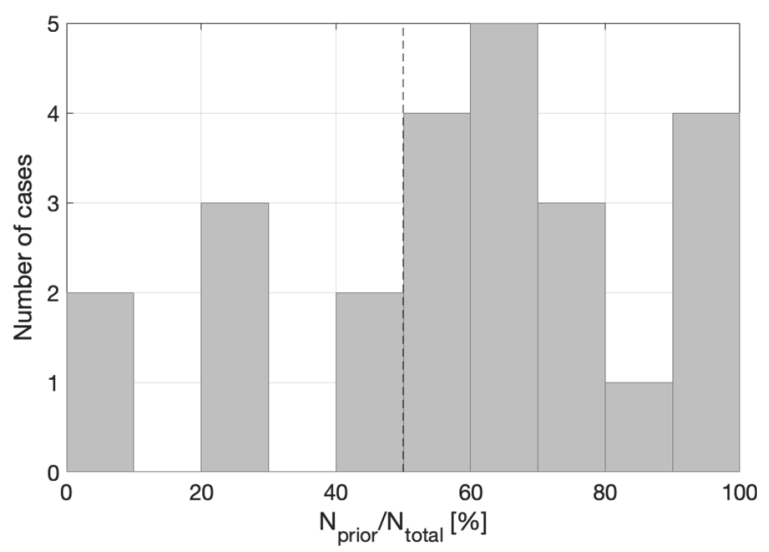

(b)

Fig. 5 Order of occurrence of the largest earthquake within each sequence. In a, we show each case in Table 1 for which catalogue data is available, with the position along the $x$-axis showing the number of events prior to the occurrence of the largest event in the sequence as a percentage of the total number of events, while the $y$-axis shows the number of total number of events within each catalogue. In $\mathbf{b}$, we show a histogram (in $10 \%$ bins) of the $N_{\text {prior }} / N_{\text {total }}$ percentage results for the cases shown in $\mathbf{a}$

\section{Next record-breaking event magnitudes}

The concept of magnitude jumps has been more commonly used by the mining industry to address induced seismicity (Cao et al., 2020). Mendecki (2016) developed the concept of the Next Record-Breaking Event (NRBE), which represents the expected size of the next event that is larger than all previous events, based on record-breaking statistics theory (Tata, 1969). Cao et al. (2020) applied this approach to oil and gas operations, including the Groningen field, and an unnamed hydraulic fracturing dataset from North America, finding that the NRBE approach performs well in estimating the observed magnitude jumps. The maximum expected magnitude jump, $\Delta M_{\mathrm{MAX}}$, is determined from the observed event population as:

$\Delta M_{\mathrm{MAX}}=2 \Delta M_{\mathrm{MAX}}^{O}-\sum_{i=1}^{n-1}\left[\left(1-\frac{i}{n}\right)^{n}-\left(1+\frac{i+1}{n}\right)^{n}\right] \Delta M_{i}^{O}$,

where $\Delta M_{\mathrm{MAX}}^{O}$ is the largest magnitude jump observed to date, and $\Delta M_{i}^{O}$ are all observed magnitude jumps ordered by size. The maximum expected magnitude jump can be added to the current largest event, $M_{\mathrm{MAX}}^{O}$, to determine the modelled magnitude of the NRBE, $M_{\mathrm{MAX}}^{M}$. Recent attempts to model the largest expected event magnitude have been based on the correlation between injection volumes and earthquake rates (e.g. Shapiro et al., 2010; Hallo et al., 2014; Mignan et al., 2017; Verdon and Budge, 2018). These methods have shown some success when applied in real time (e.g. Kwiatek et al., 2019; Clarke et al., 2019). The NRBE approach described by Mendecki (2016) provides an alternative approach that allows us to evaluate whether the observed magnitude jumps are in line with expectations given the preceding seismicity. It has the advantage of not requiring detailed injection data against which to correlate rates of seismicity, but like the methods described above, it requires a sufficient number of events to be recorded in order to establish the minimum magnitude of completeness, $M_{\mathrm{MIN}}$.

In Figs. 6, 7, and 8, we track the modelled NRBE magnitudes using Equation 1. We perform these calculations for cases where full event catalogues are available, as

Fig. 6 Next record-breaking event model applied to the UK Bowland Shale Preese Hall and Preston New Road wells. The upper panel shows observed events (grey dots) and the modelled NRBE event size (black line). The grey patch adjacent to the $x$-axis shows the injection period. The lower panel shows the modelled magnitude jump, $\Delta M_{\mathrm{MAX}}$ 

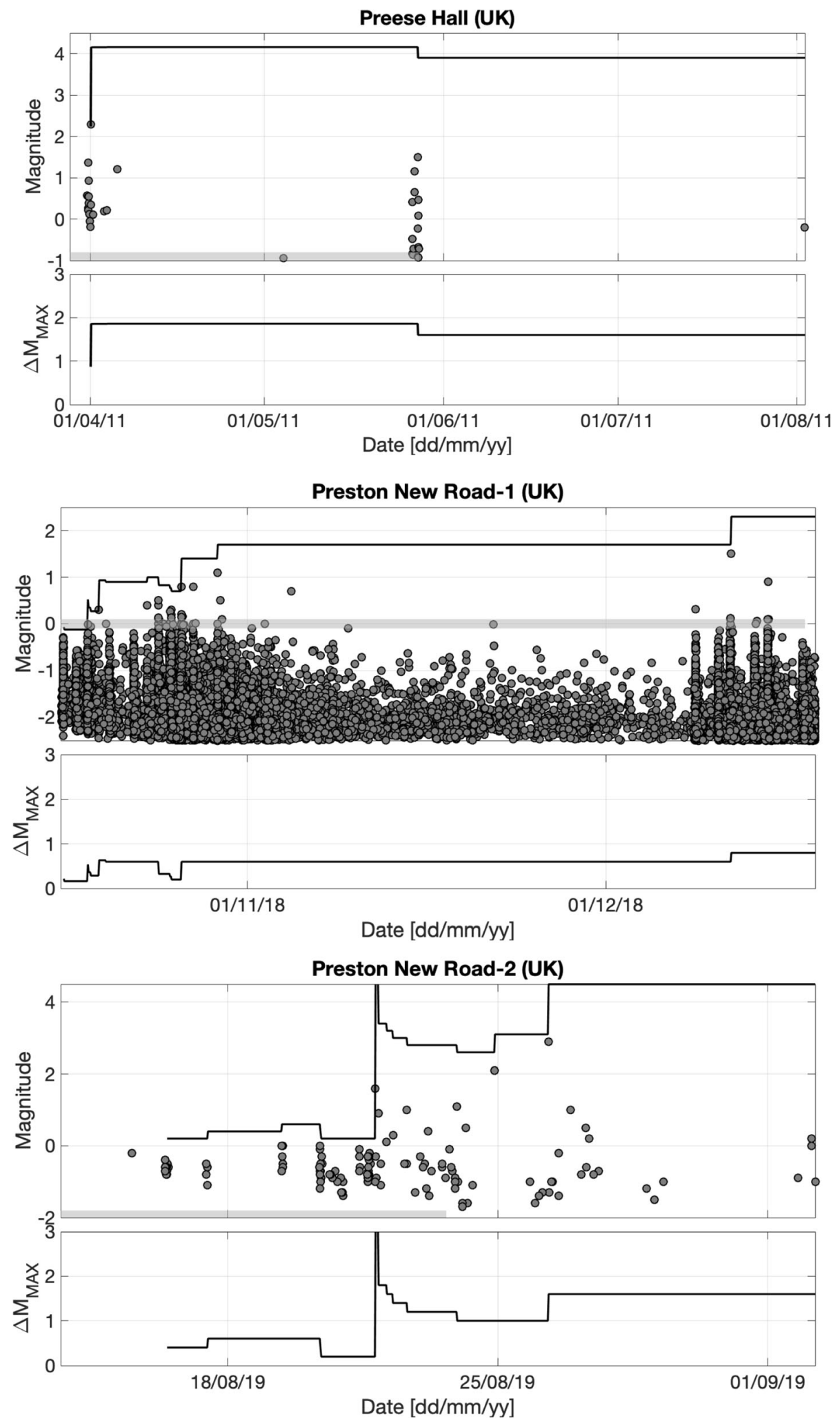

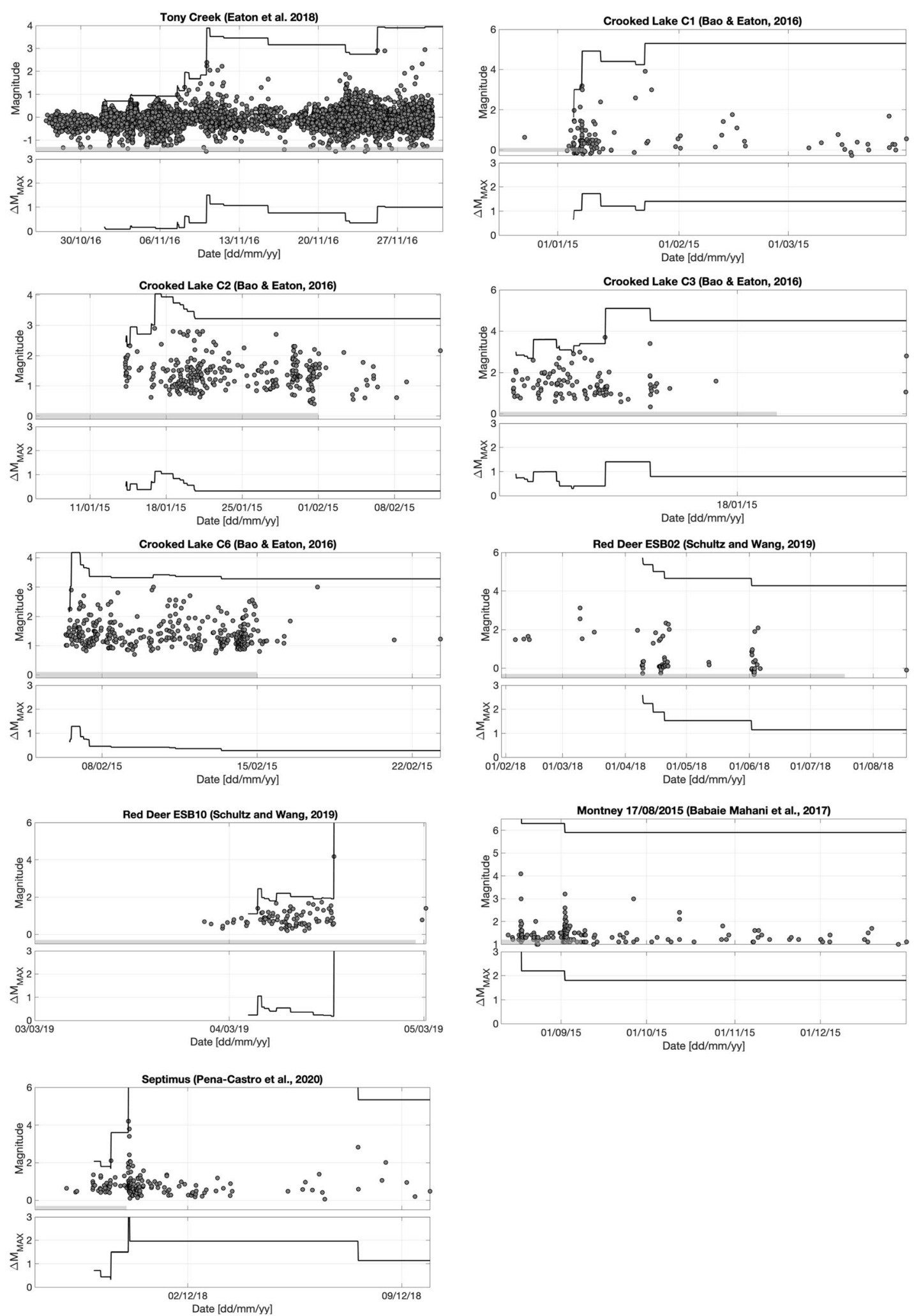

Fig. 7 Next record-breaking event model applied to cases of HF-IS in the WCSB. Figure format as per Fig. 6 

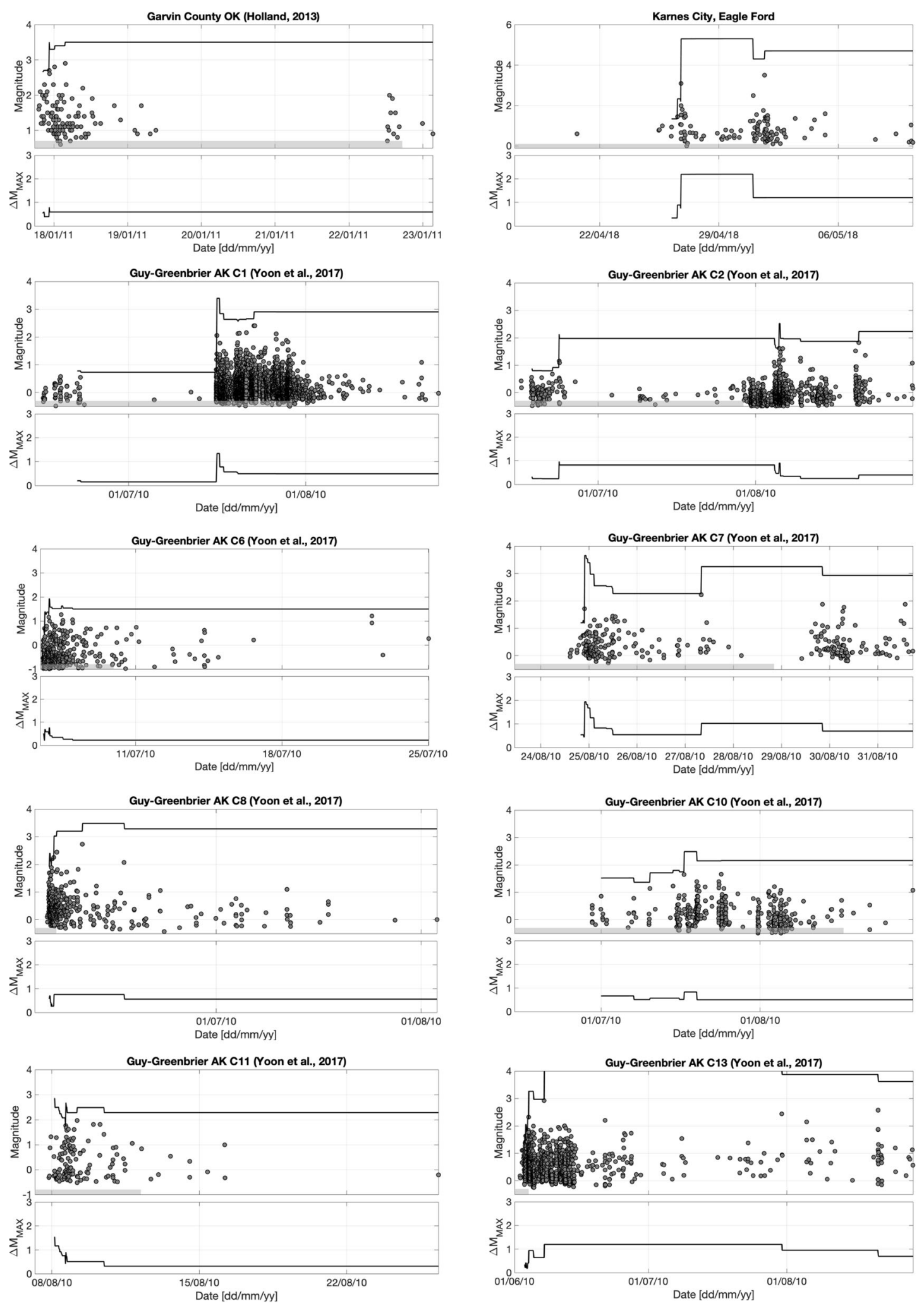

Fig. 8 Next record-breaking event model applied to cases of HF-IS in the USA. Figure format as per Fig. 6 


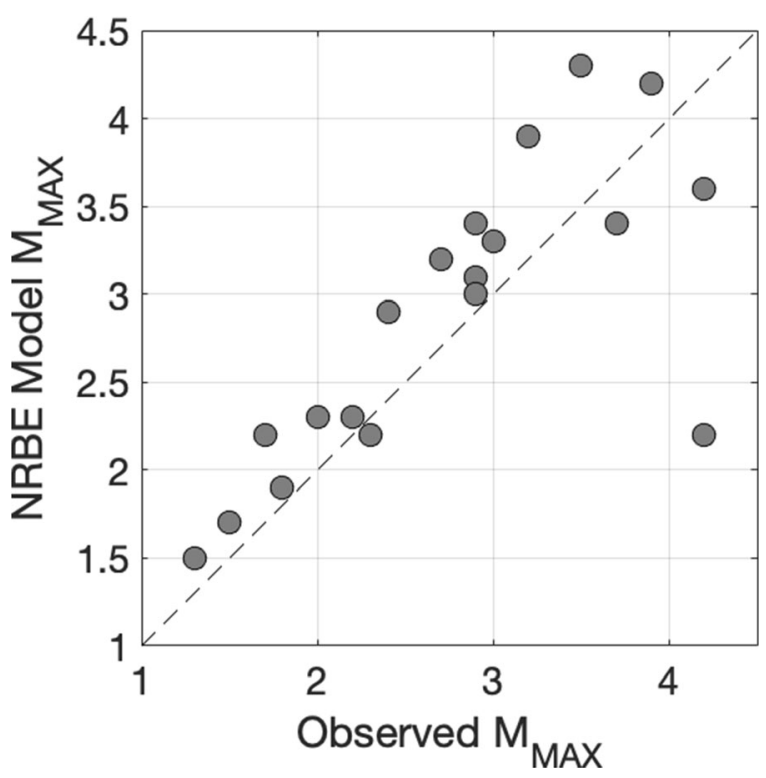

Fig. 9 Comparison of observed $M_{\mathrm{MAX}}^{O}$ (largest event size) for each of the sequences shown in Figs. 6, 7, and 8, versus the NRBE $M_{\mathrm{MAX}}^{M}$ that was modelled prior to the occurrence of this event. The dashed line shows a 1:1 relationship - the only case which does not fall close to this line is the Red Deer ESB10 cluster

opposed to the cases where we were required to digitise figures to extract datasets (see Section 4). We use the Kolmogorov-Smirnov test, with a $20 \%$ significance threshold (Clauset et al., 2009) to determine $M_{\mathrm{MIN}}$, requiring at least 30 events larger than this magnitude. This limits our analysis to the 3 UK Bowland Shale cases; the Crooked Lake clusters 1, 2, 3, and 6 (Bao and Eaton, 2016); Tony Creek (Eaton et al., 2018); the Red Deer ESB02 and ESB10 clusters (Schultz and Wang, 2020); the 2015 Montney sequence described by Babaie Mahani et al. (2017); the Septimus sequence described by Peña-Castro et al. (2020); Garvin County, OK (Holland, 2013); Karnes City (Fasola et al., 2019); and the Guy-Greenbrier clusters (Yoon et al., 2017).

In each case, we track the modelled $\Delta M_{\mathrm{MAX}}$, using Equation 1, as each sequence progresses, from which we estimate $M_{\mathrm{MAX}}^{M}$. Comparing the observed and modelled maximum magnitudes, we find that this approach does a good job of forecasting the observed magnitude jumps, with the modelled $M_{\mathrm{MAX}}^{M}$ tracking the growth in magnitudes in advance. Figure 9 compares the observed $M_{\mathrm{MAX}}^{O}$ for each of the cases with the modelled $M_{\mathrm{MAX}}^{M}$ at the timestep prior to the occurrence of this largest event, finding good agreement between the modelled and observed magnitudes.
There are, however, some exceptions to this successfor the Red Deer ESB02 and Montney 2015 cases, there were an insufficient number of events prior to the occurrence of the largest event, and hence $M_{\mathrm{MAX}}^{M}$ was undetermined at this time. For the Red Deer ESB10 case, the observed magnitude jump to the M 4.2 event is far larger than that modelled by the NRBE approach, even when the events from the preceding ESB09 cluster are included. This is the only case for which a large number of precursory events were observed and yet the NRBE approach produced a significant underestimate of $\Delta M_{\mathrm{MAX}}$.

These observations show that this method has promise for estimating magnitude jumps and, therefore, provides a viable alternative to injection volume-based methods to forecast $M_{\mathrm{MAX}}^{M}$. However, much like these volume-based methods, monitoring arrays with sufficiently low detection thresholds must be available in order to record sufficient numbers of events.

\section{Implications for TLS design and operation}

The essence of a TLS is to use monitoring of induced seismicity and pre-established thresholds for invoking modifications (reductions or suspension) of fluid injections in order to avoid shaking levels that could result in unacceptable consequences. From this perspective, the fact that for many geothermal systems and some hydraulic fracturing wells the largest induced events have occurred after shut-in has led to questioning of how effective TLS can actually be as a tool for controlling the impact of induced earthquakes (e.g. Baisch et al., 2019). However, if the patterns of jumps in the magnitude of induced events and the occurrence of trailing events are taken into account in TLS design, these systems can provide an effective means of mitigating induced seismic risk - and in many cases, offer the only possibility for rational risk management where hydraulic fracturing takes place.

\subsection{Magnitude thresholds and observation intervals}

The occurrence of magnitude jumps and trailing events appears to vary by play. For example, the Bowland Shale seems to be particularly prone to post-injection trailing event increases, while such events have also been observed in the Duvernay. In contrast, the Sichuan Basin and the Montney have produced large magnitude jumps during 
operations (or a lack of precursory events), but have not produced trailing events of any significance. While we do not have a physical explanation for this geographical variability, it is likely to be explained by different geological conditions (rock properties, structural features, in situ stresses) between plays (see Section 7.3).

We note that cases that produced large magnitude jumps during injection did not produce large trailing event magnitude increases, and vice versa. A "double whammy" effect of a large jump in magnitude during injection, followed by further increases after injection, which would pose the greatest challenge for a TLS, has not been observed in any of our case studies. If the objective of a TLS is to preclude the occurrence of a single event above a given magnitude, as opposed to preventing the occurrence of multiple large events (see Section 2), then the combined population of observed jumps and trailing event increases may provide a guide as to an appropriate separation between a red-light TLS threshold and the event magnitude that is to be avoided. We find that for $85 \%$ of the 35 cases we studied, there was no jump or trailing event larger than 2 magnitude units, while the largest confirmed jump was 2.7 magnitude units. We again note that these statistics are drawn from a biased sample because our focus is on cases where large increases in magnitude have occurred, whereas most wells undergo hydraulic stimulation without any increase in observed magnitudes at all. Nevertheless, a separation of 2-2.5 magnitude units between the TLS threshold and the magnitude to be avoided seems reasonable. Schultz et al. (2020b) reached a similar conclusion based on the theoretical consideration of potential jumps as described above, and their estimate that jumps of more than 2 units will occur in less than $1 \%$ of cases. As a result, Schultz et al. (2020b) suggested that red-light thresholds be set at a level corresponding to nuisance levels of shaking to ensure an adequate gap to account for jumps and trailing events, such that damaging levels of shaking are not reached.

Kao et al. (2018) discuss the performance of TLSs imposed to mitigate induced seismicity in the WSCB. An assumption implicit to their assessment of the TLS performance is that the objective of the TLSs was or is to prevent events that are larger than the red-light threshold of M 4. However, as we have shown, we should not expect the red-light threshold to define the limit of event magnitudes that might occur. No HF-IS events with $\mathrm{M}>5$ have occurred in the WCSB. However, since some of the M>4 HF-IS cases occurred prior to the imposition of TLSs, this may simply represent a threshold to event magnitudes imposed by the geomechanical and tectonic setting, or a statistical product of the G-R distribution of HF-IS in the WCSB, rather than any operational mitigation actions.

The UK represents a contrasting situation, where TLS red-light threshold is set at M 0.5, yet an M 2.9 event occurred under this scheme. It is therefore worth examining the operation of this scheme in more detail. While the M 0.5 limit is the most conservative of any TLS applied to hydraulic fracturing, the consequences of breaching the red light are the least onerous, with a pause in injection of a minimum of $18 \mathrm{~h}$ being required after which, once seismicity levels have decreased below M 0.5, further injection may occur (Clarke et al., 2019). This was the case at the Preston New Road wells, where the red light was triggered on multiple occasions. Most notably, during PNR-2 the red-light threshold was reached with an M 1.6 event on the 21st August 2019, but further injection took place on the 23rd August 2019, after which the M 2.9 event occurred (Kettlety et al. 2020). Evidently, the pause in injection did little to reduce the cumulative impact of injection, with event magnitudes continuing to rise after injection re-started.

A more extreme example of this effect took place at the Pohang geothermal operation in South Korea, where an M 5.5 event occurred (Ellsworth et al., 2019), despite a TLS with a red light of M 2.0 (Kim et al., 2018). However, while the red-light threshold was reached with an M 3.2 event in April 2017, further injection took place in August and September 2017, after which the M 5.5 event occurred. Observations from sites such as Preston New Road and Pohang indicate that once a fault has been activated by fluid injection, it may remain prone to continued activation by further injection, even after a substantial period of time, with magnitude levels continuing to develop from where they were during previous injection phases, as opposed to resetting to much reduced levels. While it might be anticipated that extensive flowback could act to reduce the levels of stress acting on a reactivated fault, and thereby reduce the levels of seismicity should further injection take place, we are not aware of any studies that have yet demonstrated this in practice.

\subsection{TLSs and maximum magnitudes}

In order to obtain a licence for a HF operation, it is likely that operators will need to present a safety case that demonstrates that the injections will not lead to unacceptable 
levels of seismic risk. This may include hazard or risk assessments, in which a key parameter to be defined would be the largest magnitude event expected to occur. If the assessments are made deterministically, then the size of this postulated largest event will largely control the impacts. If a probabilistic approach is adopted, the maximum magnitude will define the upper limits of the hazard integration. In either case, the value will be difficult to estimate with a high degree of certainty and, at the same time, the perception of the viability of the project will be strongly influenced by the value of maximum magnitude, $M_{\mathrm{MAX}}$. Considerable effort has been invested over recent decades to define $M_{\mathrm{MAX}}$ for probabilistic seismic hazard analysis (PSHA) for natural seismicity, despite the fact that this parameter is generally found to exert relatively little influence on hazard estimates. For induced seismicity, $M_{\mathrm{MAX}}$ can be more influential but it could also be argued that $M_{\text {MAX }}$ has different meanings in hazard assessments for natural and induced seismicity. In long-term PSHA, the value corresponds to the largest earthquake that could ever occur within a given seismic source during the current tectonic regime. For induced earthquakes, it corresponds to the largest event that could be triggered by the fluid injection, and therefore must occur during or shortly after injection which, for hydraulic fracturing, will correspond to a period typically measured in days or weeks (Fig. 1). While the distinction is subtle, it is very important: we believe that simply assuming the same $M_{\mathrm{MAX}}$ values used in PSHA for natural seismicity when estimating seismic hazard and risk due to induced earthquakes could lead to gross overestimation in many cases. In PSHA for tectonic seismicity, it is perfectly reasonable to constrain $M_{\mathrm{MAX}}$ based on the dimensions of the largest seismogenic faults, but for induced seismicity from short-lived operations, the largest magnitude earthquake may depend on numerous operational factors and hydraulic connectivity between the injection wells and any critically stressed faults, as well as the dimensions of such faults. We would argue, therefore, that approaches to estimating $M_{\mathrm{MAX}}$ for induced and natural seismicity should be different.

McGarr (2014) proposed that the largest earthquake is controlled by the total volume of injected fluid, whereas van der Elst et al. (2016) have argued that this volume controls the number of earthquakes and that the largest earthquake is actually controlled by the tectonics of the region (although they also note that the largest event is proportional to the total number of earthquakes, thereby linking $M_{\mathrm{MAX}}$ back to volume). The findings of van der Elst et al. (2016) would seem to support those who propose that $M_{\mathrm{MAX}}$ for induced earthquakes is the same as for tectonic earthquakes in a given region (e.g. Petersen et al., 2015), but this point of view has not been universally accepted. Although related to long-term conventional natural gas production rather than short-lived fluid injection, induced seismicity in the Groningen gas field in the Netherlands serves as an example of how the two estimates of $M_{\text {MAX }}$ may vary. In the SHARE project that produced seismic hazard maps for Europe, the logic-tree branches for $M_{\mathrm{MAX}}$ in the region containing the Groningen field were all $\geq 6.5$ (Woessner et al., 2015), whereas studies focussed on induced seismicity in the field proposed maximum magnitudes in the range of 4.0-4.5 (Zöller and Holschneider, 2016; Dempsey and Suckale, 2017; Beirlant et al., 2019); the largest observed earthquake to date was of magnitude M 3.6. A panel of international experts charged with making an assessment of $M_{\mathrm{MAX}}$ in Groningen developed a logic-tree that assigned a probability of almost $75 \%$ that $M_{\mathrm{MAX}}$ would be no more than 1.5 magnitude units greater than the largest observed event and a probability of less than $10 \%$ to $M_{\mathrm{MAX}}$ being equal to that assigned for tectonic seismicity (Bommer and van Elk, 2017). Moreover, at the time of writing, the expert panel has been reconvened for a second workshop to consider new information regarding the possibility of the compaction of the gas reservoir triggering tectonic earthquakes.

The depth of earthquake nucleation is an important issue in the consideration of appropriate $M_{\mathrm{MAX}}$ values. Large tectonic earthquakes tend to occur at mid-crustal depths, with a large portion of the rupture propagating upwards from the hypocentre (e.g. Mai and Thingbaijam, 2014). Events induced by hydrocarbon activities typically occur in the sedimentary column, or within the upper km of the underlying basement (e.g. Verdon, 2014). Therefore, the triggering of large-magnitude earthquakes would require that a fault rupture is initiated which proceeds to propagate mainly downwards into the crust. Whether such a mechanism is likely to occur is open to debate but the available evidence suggests that fault ruptures that propagate exclusively downwards are very rare. Mai et al. (2005) present a database of more than 50 finite rupture models for both strike-slip and dip-slip earthquakes: in only 6 of the cases is the hypocentre located in the upper third of the rupture width and none in the top $15 \%$ of the rupture width. Lomax (2020) reports a focal depth of just $4 \mathrm{~km}$ for the M 7.1 Ridgecrest mainshock "implying nucleation in a zone not conducive to spontaneous, large earthquake rupture nucleation and growth." Lomax (2020) argues that this shallow hypocentre was the result 
of stress transfer from a deeper $(12 \mathrm{~km})$ foreshock of $\mathrm{M}$ 6.4 , without which rupture initiation of a large event at such shallow depth would not have occurred.

The onus on operators to assess a priori the largest earthquake magnitude that might be expected is reduced when a TLS is implemented, especially if such a system is designed to take magnitude jumps and trailing events into account, rather than considering these as cases of TLS failing in their objectives. By establishing an appropriate red-light threshold and allowing for the potential jump above this level, a system can be designed with reasonable confidence of maintaining induced seismicity at an acceptable level. The operation of a TLS can be further refined and improved through the use of observational data in real time to continuously update estimates of the largest expected magnitudes using either methods based on correlations between volume and earthquake rate (e.g. Shapiro et al., 2010; Hallo et al., 2014) or methods based on the NRBE concept (Mendecki, 2016; Cao et al., 2020).

7.3 Influence of stress conditions on the evolution of HF-IS sequences

We have shown throughout this study that there is large variability in the induced seismicity response between different formations and between different geographical regions. It is well established that the occurrence of HF-IS requires certain necessary conditions, including the presence of pre-existing tectonic faults that are near to their Mohr-Coulomb critical stress threshold at which slip can occur. Hence, both the abundance of faulting and the in situ stress conditions are likely to play important roles in the evolution of HF-IS sequences.

As an example, at the Preston New Road site in the UK, Kettlety et al. (2020) identified that the different orientations of the two reactivated faults may account for their different responses. The PNR-1z fault, which was moderately well orientated in the in situ stress field, saw a gradual increase in magnitudes over time, whereas the PNR2 fault, which was very well orientated in the in situ stress field, reactivated after a much smaller volume had been injected, and produced larger magnitude jumps and trailing events.

While detailed stress information on a site by site basis is often not available, it is of interest to consider the general stress conditions for the different plays and formations identified in Table 1, as revealed by the focal mechanisms of recorded events. The only HF-IS case study from Table 1 which appears to have extensional stress conditions $\left(S_{\mathrm{hmin}}<S_{\mathrm{H} \max }<S_{V}\right.$, where $S_{\mathrm{hmin}}$, $S_{\text {Hmax }}$, and $S_{V}$ are the minimum horizontal, maximum horizontal, and vertical principal stress components, respectively) was the Karnes case from the Eagle Ford Shale (Fasola et al., 2019). The majority of cases of HFIS appear to be from sites with strike-slip stress conditions $\left(S_{\mathrm{hmin}}<S_{V}<S_{\mathrm{Hmax}}\right)$, including the UK Bowland Shale (e.g. Clarke et al., 2014), the Duvernay (e.g. Eaton et al., 2018), the Appalachian Basin (e.g. Skoumal et al., 2015), Arkansas (e.g. Yoon et al., 2017), and Oklahoma (e.g. McNamara et al., 2015).

Two cases of HF-IS show evidence of compressional stress conditions $\left(S_{\mathrm{hmin}}<S_{\mathrm{H} \max }<S_{V}\right)$ : the Montney shale (e.g. Peña-Castro et al., 2020) and the Sichuan Basin (e.g. Jia et al., 2020). We note that these two plays represent the two most extreme cases of HF-IS, with the Sichuan Basin hosting the largest HF-IS events yet recorded, with the Montney shale being the secondlargest, and also showing the most extreme examples of magnitude jumps during injection.

This behaviour might be expected when these stress regimes are considered in more detail. It is widely held that the crust is critically stressed (Zoback et al., 2002). While it may be argued that this concept does not apply in all settings (e.g. Vilarrasa and Carrera, 2015), it is reasonable to assume that sites that are susceptible to induced seismicity will be near to the critical stress state. As such, the stress conditions will be controlled by the frictional properties of faults, as shown schematically in Fig. 10. The vertical stress is generated by the weight of the overburden, and so is primarily controlled by depth. In an extensional regime, the horizontal stresses must be lower than $S_{V}$. Given the positive slope of the Mohr-Coulomb failure envelope, the shear stresses must therefore be relatively small. In contrast, in a compressional regime, the horizontal stresses must be larger than $S_{V}$. As such, for the same depth (and therefore the same value of $S_{V}$ ), the shear stresses will be significantly larger. A strike-slip regime, where the $S_{V}$ is interposed between maximum and minimum horizontal stresses, results in shear stresses that will be lower than compressional regimes, but higher than extensional regimes. 


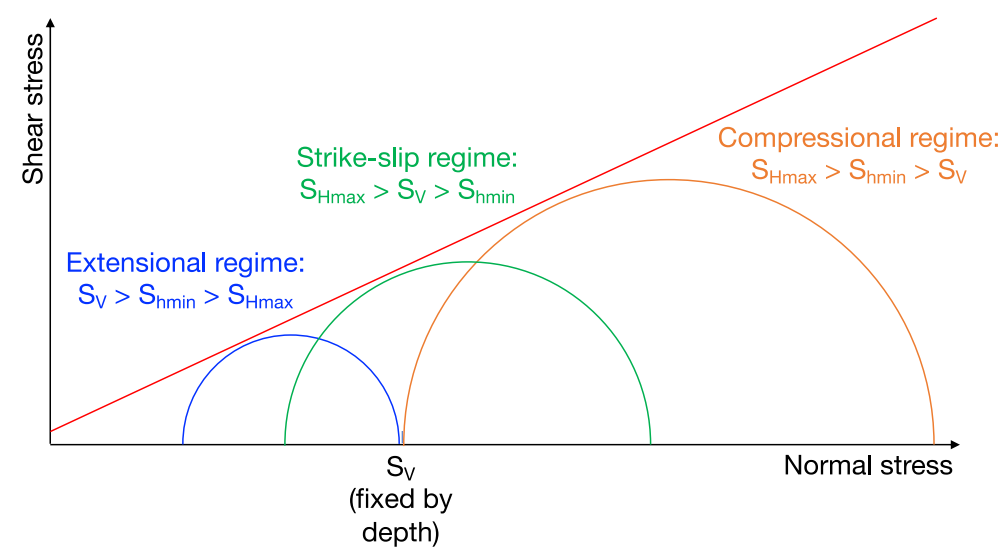

Fig. 10 Schematic depiction of the impact of stress regime (extensional, blue; strike-slip, green; compressional, orange) on the shear stress that might be experienced by faults. We show Mohr circles for each stress condition, on the condition that the

It can be surmised that HF-IS will generate larger magnitudes, and larger magnitude jumps, in conditions where shear stresses acting on faults are higher. The observations presented above are consistent with this concept. While hydraulic fracturing has been conducted in many formations with extensional stress conditions, such as the Barnett Shale, cases of HF-IS are rare. Cases of HF-IS become more common in strike-slip settings, although magnitudes have been moderate, and a gradual evolution of magnitudes is typically observed, with few large magnitude jumps. Hydraulic fracturing in formations with compressional stress conditions is less common. However, where such activities have taken place, event magnitudes have been larger, and more extreme jumps in magnitudes have been observed.

\section{Conclusions}

Hydraulic fracturing-induced seismicity continues to pose an issue for the shale gas industry in various regions and plays around the world. Traffic Light Schemes are widely used as a tool to regulate and mitigate HF-IS hazards. The effective use of TLSs requires that appropriate thresholds be set, both with respect to the risk target in terms of consequences to be avoided, and with respect to the ability of TLSs to ensure that events with potential to produce said risks do not occur. TLS thresholds may be based on event magnitudes or observed ground motions (or a combination of the two). Whereas ground motions may be more closely related to earthquake impacts, accurate characterisations of ground motion may be more challenging to make unless vertical stress, $S_{V}$, is fixed by depth, and that stress conditions are close to the Mohr-Coulomb failure criteria (red line). As such, the extensional regime produces lower shear stresses, while the compressional regime produces higher shear stresses

dense local networks are available. Equally, the impacts of jumps in event size and post-injection trailing effects are more easily quantified with respect to magnitude. Hence, magnitudes may be the optimal parameter on which to base TLS thresholds. However, choices of magnitude thresholds should reflect the expected ground motions that would result given the anticipated event locations, depths, and near-surface conditions, relative to the vulnerability of nearby buildings and infrastructure.

TLSs are underpinned by two key assumptions: that magnitudes increase relatively gradually during injection, allowing mitigative actions to be taken as magnitudes proceed from green to yellow to red and that the mitigating action (e.g. ceasing injection) will stop or reduce the earthquake magnitudes. These assumptions are challenged by observations of magnitude jumps, whereby an event occurs that is significantly larger than any event in the preceding sequence ("out-of-the-blue"), and by trailing events, where magnitudes continue to increase after injection has ceased. The extent to which these phenomena are able to occur will determine the appropriate separation between TLS thresholds and the levels that are to be avoided.

To address this question, we have assembled HF-IS datasets from around the world. We find that magnitude jumps of up to 1 unit are common, while jumps that are significantly larger than 2 magnitude units are rare, with the largest observed jumps being 2.7. Trailing event magnitude increases occur in approximately one quarter of cases, with very few cases having a trailing event increase larger than 1 unit. Sequences where large jumps occurred during injection did not produce trailing events, and vice 
versa, meaning that the double impact of these two effects has not been observed. As such, based on the observed cases, a separation of 2-2.5 units between the red-light threshold and the magnitudes that are to be avoided would seem reasonable.

The concept of magnitude jumps during induced seismicity sequences has also been addressed by the mining industry, where the concept of the next record-breaking event has been developed. We applied this method to our compiled datasets and found that the NRBE approach was generally successful in forecasting event magnitudes. However, there remained a minority of cases where either the largest event either had too few precursors to make an NRBE forecast or where the forecast underpredicted the largest event. Therefore, while such forecasting schemes will undoubtably provide useful guidance for regulators and operators during injection (e.g. Kwiatek et al., 2019; Clarke et al., 2019), we anticipate that TLSs, so long as they are appropriately designed, will continue to play an important role in the successful mitigation of HF-IS.

Acknowledgments We would like to thank the Associate Editor, Thomas Braun, and Ryan Schultz and Gail Atkinson for their helpful comments on our original manuscript. We would also like to thank Ernie Rutter for helpful discussion regarding the influence of stress regimes on the occurrence of induced seismicity.

Funding James Verdon's contribution to this study was funded by the Natural Environment Research Council (NERC) under the UK Unconventional Hydrocarbons Project, Challenge 2 (Grant No. NE/R018162/1).

Compliance with ethical standards Both authors have acted as independent consultants for a variety of organisations including hydrocarbon operating companies and governmental organisations on issues pertaining to induced seismicity.

All data used in this paper is available publicly in the references outlined in Table 1. Both authors contributed equally to the analysis and writing of the paper.

Open Access This article is licensed under a Creative Commons Attribution 4.0 International License, which permits use, sharing, adaptation, distribution and reproduction in any medium or format, as long as you give appropriate credit to the original author(s) and the source, provide a link to the Creative Commons licence, and indicate if changes were made. The images or other third party material in this article are included in the article's Creative Commons licence, unless indicated otherwise in a credit line to the material. If material is not included in the article's Creative Commons licence and your intended use is not permitted by statutory regulation or exceeds the permitted use, you will need to obtain permission directly from the copyright holder. To view a copy of this licence, visit http://creativecommons.org/licenses/by/4.0/.

\section{References}

Ader T, Chendorain M, Free M, Ssarno T, Heikkinen P, Malin PE, Leary P, Kwiatek G, Dresen G, Bluemi F, Vuorinen T (2019) Design and implementation of a traffic light system for deep geothermal well stimulation in Finland. In: Design and implementation of a traffic light system for deep geothermal well stimulation in. Journal of Seismology, Finland. https://doi.org/10.1007/s10950-019-09853-y

Atkinson GM (2020) The intensity of ground motions from induced earthquakes with implications for damage potential. Bull Seismol Soc Am 110:2366-2379. https://doi. org/10.1785/0120190166

Atkinson GM, Eaton DW, Ghofrani H, Walker D, Cheadle B, Schultz R, Shcherbakov R, Tiampo K, Gu J, Harrington RM, Liu Y, van der Baan M, Kao H (2016) Hydraulic fracturing and seismicity in the Western Canadian Sedimentary Basin. Seismol Res Lett 87:1-17

Atkinson GM, Wald D, Worden CB, Quitoriano V (2018) The intensity signature of induced seismicity. Bull Seismol Soc Am 108:1080-1086

Babaie Mahani A, Schultz R, Kao H, Walker D, Johnson J, Salas C (2017) Fluid injection and seismic activity in the Northern Montney Play, British Columbia, Canada, with special reference to the 17 August 2015 MW 4.6 induced earthquake. Bull Seismol Soc Am 107:542-552

Babaie Mahani A, Kao H, Atkinson GM, Assatourians K, Addo K, Liu Y (2019) Ground-motion characteristics of the 30 November 2018 injection-induced earthquake sequence in northeast British Columbia, Canada. Seismol. Res. Lett 90: $1457-1467$

Baisch S, Koch C, Muntendam-Bos A (2019) Traffic light systems: to what extent can induced seismicity be controlled. Seismol. Res. Lett 90:1145-1154

Bao X, Eaton DW (2016) Fault activation by hydraulic fracturing in western Canada. Science 354:1406-1409

BC Oil and Gas Commission, 2012. Investigation of observed seismicity in the Horn River Basin. B.C. Oil and Gas Commission: Available online at https://www.bcogc. ca/node/8046/download

BC Oil and Gas Commission, 2014. Investigation of observed seismicity in the Montney Trend. B.C. Oil and Gas Commission: Available online at https://www.bcogc. ca/node/12291/download

Beirlant J, Kijko A, Reynkens T, Einmahl JHJ (2019) Estimating the maximum possible earthquake magnitude using extreme value methodology: the Groningen case. Nat Hazards 98: $1091-1113$

Bommer JJ, Alarcón JE (2006) The prediction and use of peak ground velocity. J Earthq Eng 10:1-31

Bommer JJ, Crowley H (2017) The purpose and definition of the minimum magnitude limit in PSHA calculations. Seismol Res Lett 88:1097-1106

Bommer JJ, van Elk J (2017) Comment on "The maximum possible and maximum expected earthquake magnitude for production-induced earthquakes at the gas field in Groningen, the Netherlands" by Gert Zöller and Matthias Holschneider. Bull Seismol Soc Am 107:1564-1567

Bommer JJ, Oates S, Cepeda JM, Lindholm C, Bird JF, Torres R, Marroquín G, Rivas J (2006) Control of hazard due to 
seismicity induced by a hot fractured rock geothermal project. Eng Geol 83:287-306

Bommer JJ, Crowley H, Pinho R (2015) A risk-mitigation approach to the management of induced seismicity. J Seismol 19:623-464

BSI, 2008. Guide to evaluation of human exposure to vibration in buildings - Part 2: Blast-induced vibration, BS 6472-2:2008: British Standards Institute, London, $24 \mathrm{pp}$.

Butcher A, Luckett R, Verdon JP, Kendall J-M, Baptie B, Wookey J $(2017,107)$ Local magnitude discrepancies for near-event receivers; implications for the UK traffic light scheme. Bull Seismol Soc Am:532-541

Cao N-T, Eisner L, Jechumtálová Z (2020) Next record breaking magnitude for injection induced seismicity. First Break 38:53-57

Clarke H, Eisner L, Styles P, Turner P (2014) Felt seismicity associated with shale gas hydraulic fracturing: The first documented example in Europe. Geophys.Res.Lett 41:8308-8314

Clarke H, Verdon JP, Kettlety T, Baird AF, Kendall J-M (2019) Real time imaging, forecasting and management of human-induced seismicity at Preston New Road, Lancashire, England. Seismol. Res. Lett 90:1902-1915

Clauset A, Shalizi CR, Newman MEJ (2009) Power-law distributions in empirical data. SIAM Rev Soc Ind Appl Math 51:661-703

Cremen G., M.J. Werner, B. Baptie, 2020. A new procedure for evaluating ground-motion models, with application to hydraulic-fracture-induced seismicity in the United Kingdom: https://doi.org/10.1785/0120190238

Darold A, Holland AA, Chen C, Youngblood A (2014) Preliminary analysis of seismicity near Eagleton 1-29, Carter County, July 2014: Oklahoma Geological Society Open File Report, OF2-2014

Dempsey D, Suckale J (2017) Physics-based forecasting of induced seismicity at Groningen gas field, the Netherlands. Geophys Res Lett 44:7773-7782

Douglas J, Aochi H (2014) Using estimated risk to develop stimulation strategies for enhanced geothermal systems. Pure Appl Geophys 171:1847-1858

Eaton DW, Igonin N, Poulin A, Weir R, Zhang H, Pellegrino S, Rodriguez G (2018) Induced seismicity characterization during hydraulic-fracture monitoring with a shallow-wellbore geophone array and broadband sensors. Seismol Res Lett, 1651 89:1641

Ellsworth WL, Giardini D, Townend J, Ge S, Shimamoto T (2019) Triggering of the Pohang, Korea, earthquake $\left(M_{W} 5.5\right)$ by enhanced geothermal system stimulation. Seismol. Res. Lett 90:1844-1858

Eyre TS, Eaton DW, Zecevic M, D’Amico D, Kolos D (2019) Microseismicity reveals fault activation before $\mathrm{M}_{\mathrm{W}} 4.1$ hydraulic-fracturing induced earthquake. Geophys J Int 218:534-546

Farahbod AM, Kao H, Walker DM, Cassidy JF (2015) Investigation of regional seismicity before and after hydraulic fracturing in the Horn River basin, Northeast British Columbia. Can J Earth Sci 52:112122

Fasola SL, Brudzinski MR, Skoumal RJ, Langenkamp T, Currie BS, Smart KJ (2019) Hydraulic fracture injection strategy influences the probability of earthquakes in the Eagle Ford
Shale play of south Texas. Geophys Res Lett 46:1295812967

Fereidoni A. L. Cui, 2015. Composite Alberta Seismicity Catalog: CASC2014-x. Available at https://www.inducedseismicity. ca/wp-content/uploads/2015/01/Composite-AlbertaSeismicity-Catalog3.pdf

Friberg PA, Besana-Ostman GM, Dricker I (2014) Characterisation of an earthquake sequence triggered by hydraulic fracturing in Harrison County, Ohio. Seismol. Res. Lett 85:1295-1307

Gutenberg B, Richter CF (1944) Frequency of earthquakes in California: Bulletin of Seismological Society of America. 34:185-188

Hallo M, Oprsal I, Eisner L, Ali MY (2014) Prediction of magnitude of the largest potentially induced seismic event. J Seismol 18:421-431

Hanks TC, Johnson DA (1976, 66) Geophysical assessment of peak accelerations. Bull Seismol Soc Am:959-968

Häring MO, Schanz U, Ladner F, Dyer BC (2008) Characterisation of the Basel 1 enhanced geothermal system. Geothermics 37:469-495

Holland AA (2013) Earthquakes triggered by hydraulic fracturing in south-central Oklahoma. Bull Seismol Soc Am 103:17841792

Horton S (2012) Injection into subsurface aquifers triggers earthquake swarm in central Arkansas with potential for damaging earthquake. Seismol Res Lett 83:250-260

Hough SE (2014) Shaking from injection-induced earthquakes in the central and eastern United States. Bull Seismol Soc Am 104:2619-2626

Jia K, Zhou S, Zhuang J, Jiang C, Guo Y, Gao Z, Gao S, Ogata Y, Song X (2020) Nonstationary background seismicity rate and evolution of stress changes in the Changning salt mining and shale-gas hydraulic fracturing region, Sichuan Basin, China. Seismol. Res. Lett 91:2170-2181

Kao H, Visser R, Smith B, Venables S (2018) Performance assessment of the induced seismicity traffic light protocol for northeastern British Columbia and western Alberta. Lead Edge 37:117-126

Kendall J-M, Butcher A, Stork AL, Verdon JP, Luckett R, Baptie BJ (2019) How big is a small earthquake? Challenges in determining microseismic magnitudes. First Break 37:51-56

Keranen KM, Savage HM, Abers GA, Cochran ES (2013) Potentially induced earthquakes in Oklahoma: USA: links between wastewater injection and the $2011 \mathrm{M}_{\mathrm{W}} 5.7$ earthquake sequence. Geology 41:699-702

Kettlety T, Verdon JP, Hampson M, Craddock L (2020) The $\mathrm{M}_{\mathrm{L}}$ 2.9 August 2019 earthquake in Lancashire, UK, induced by hydraulic fracturing during Preston New Road PNR-2 operations: Seismological Research Letters. https://doi. org/10.1785/0220200187

Kim W-Y (2013) Induced seismicity associated with fluid injection into a deep well in Youngstown, Ohio. J. Geophys. Res 118:3506-3518

Kim K-I, Mina K-B, Kim K-Y, Choi JW, Yoon K-S, Yoon WS, Yoon B, Lee TJ, Song Y (2018) Protocol for induced microseismicity in the first enhanced geothermal systems project in Pohang, Korea. Renew.Sust. Energ.Rev 91:1182-1191

Kwiatek, G., T. Saamo, T. Ader, F. Bluemle, M. Bohnhoff, M. Chendorain, G. Dresen, P. Heikkinen, I. Kukkonen, P. Leary, M. Leonhardt, P. Malin, P. Martinez-Garzon, K. Passmore, 
P. Passmore, S. Valenzuela, C. Wollin, 2019. Controlling fluid-induced seismicity during a 6.1-km-deep geothermal stimulation in Finland: Science Advances 5, eaav7224

Langenbruch C, Zoback MD (2016) How will induced seismicity in Oklahoma respond to decreased saltwater injection rates? Sci Adv 2:e1601542

Lei X, Huang D, Su J, Jiang G, Wang X, Wang H, Guo X, Fu H (2017) Fault reactivation and earthquakes with magnitudes up to $\mathrm{M}_{\mathrm{W}} 4.7$ induced by shale-gas hydraulic fracturing in Sichuan Basin, China. Sci Rep 7:7971

Lei X, Wang Z, Su J (2019a) The December $2018 \mathrm{M}_{\mathrm{L}} 5.7$ and January $2019 \mathrm{M}_{\mathrm{L}} 5.3$ earthquakes in South Sichuan Basin induced by shale gas hydraulic fracturing. Seismol Res Lett 90:1099-1110

Lei X, Wang Z, Su J (2019b) Possible link between long-term and short-term water injections and earthquakes in salt mine and shale gas site in Changning, South Sichuan Basin, China. Earth Planet Phys 3:510-525

Baird, B.W, A.B. Liel, R.E. Chase, 2020. Magnitude thresholds and spatial footprints of damage from induced earthquakes: Earthquake Spectra, https://doi.org/10.1177 /8755293020935138, 875529302093513

Liu J, Zahradník J (2020) The $2019 \mathrm{M}_{\mathrm{W}} 5.7$ Changning earthquake, Sichuan Basin, China: a shallow doublet with different faulting styles. Geophys Res Lett 47:e2019GL085408

Lomax, A., 2020. Absolute location of 2019 Ridgecrest seismicity reveals a shallow $M_{w} 7.1$ hypocenter, migrating and pulsing $\mathrm{M}_{\mathrm{w}} 7.1$ foreshocks, and duplex $\mathrm{M}_{\mathrm{w}} 6.4$ ruptures:Bulletin of the Seismological Society of America, https://doi. org/10.1785/0120200006

Mai PM, Thingbaijam KKS (2014) SRCMOD: an online database of finite-fault rupture models. Seismol. Res. Lett 85:13481357

Mai PM, Spudich P, Boatwright J (2005) Hypocenter location in finite-source ruoture models. Bull Seismol Soc Am 95(3): 965-980

Majer E, Baria R, Stark M, Oates S, Bommer J, Asanuma H (2007) Induced seismicity associated with enhanced geothermal systems. Geothermics 3:185-222

Majer E, Nelson J, Robertson-Tait A, Savy J, Wong I (2012) Protocol for addressing induced seismicity associated with enhanced geothermal systems: DOE/EE-0662. Energy, US Department of

McGarr A (2014) Maximum magnitude earthquakes induced by fluid injection. J Geophys Res 119:1008-1019

McNamara DE, Benz HM, Herrmann RB, Bergman EA, Earle P, Holland A, Baldwin R, Gassner A (2015) Earthquake hypocenters and focal mechanisms in central Oklahoma reveal a complex system of reactivated subsurface strike-slip faulting. Geophys Res Lett 42:2742-2749

Mena B, Wiemer S, Bachmann C (2013) Building robust models to forecast induced seismicity related to geothermal reservoir enhancement. Bull Seismol Soc Am 103:383-393

Mendecki AJ (2016) Mine Seismology Reference Book: Seismic Hazard: Institute of Mine Seismology. Tasmania, Australia

Meng L, McGarr A, Zhou L, Zang Y (2019) An investigation of seismicity induced by hydraulic fracturing in the Sichuan Basin of China based on data from a temporary seismic network. Bull Seismol Soc Am 109:348-357

Mignan A, Broccardo M, Wiemer S, Giardini D (2017) Induced seismicity closed-form traffic light system for actuarial decision-making during deep fluid injections. Nat Sci Rep 7:13607

Nievas CI, Bommer JJ, Crowley H, van Elk J, Ntinalexis M, Sangirardi M (2020a) A database of damaging small-tomedium magnitude earthquakes. J. Seismol 24:263-292. https://doi.org/10.1007/s10950-019-09897-0

Nievas CI, Bommer JJ, Crowley H, van Elk J (2020b) Global occurrence and impact of small-to-medium magnitude earthquakes: a statistical analysis. Bull Earthq Eng 18:1-35

NRC (2012) Induced seismicity potential in energy technologies. National Research Council, The National Academies Press, Washington D.C, 300 pp

Peña-Castro AF, Roth MP, Verdecchia A, Onwuemeka J, Liu Y, Harrington RM, Zhang Y, Kao H (2020) Stress chatter via fluid flow and fault slip in a hydraulic fracturing induced earthquake sequence in the Montney formation, British Columbia. Geophysical Research Letters 47: e2020GL087254

Petersen, M.D., C.S. Mueller, M.P. Moschetti, S.M. Hoover, J.L. Rubinstein, A.L. Llenos, A. J. Michael, W.L. Ellsworth, A.F. McGarr, A.A. Holland, J.G. Anderson, 2015. Incorporating induced seismicity in the 2014 United States National Seismic Hazard Model - results of 2014 workshop and sensitivity studies: USGS Open-File Report 2015-1070, US Geological Survey, Reston, VA

Roth MP, Verdecchia A, Harrington RM, Liu Y (2020) Highresolution imaging of hydraulic fracturing-induced earthquake clusters in the Dawson-Septimus area, northeast British Columbia, Canada. Seismol Res Lett. https://doi. org/10.1785/0220200086

Rubenstein JL, Babaie Mahani A (2015) Myths and facts on wastewater injection, hydraulic fracturing, enhanced oil recovery, and induced seismicity. Seismological Research Letters 86:1060-1067

Schultz R, Wang R (2020) Newly emerging cases of hydraulic fracturing induced seismicity in the the Duvernay East shale basin. Tectonophysics 779:228393

Schultz R, Stern V, Novakovic M, Atkinson G, Gu YJ (2015a) Hydraulic fracturing and the crooked Lake sequences: insights gleaned from regional seismic networks. Geophys Res Lett 42:2750-2758

Schultz R, Mei S, Pana D, Stern V, Gu YJ, Kim A, Eaton D (2015b) The Cardston earthquake swarm and hydraulic fracturing of the Exshaw formation (Alberta Bakken play). Bull Seismol Soc Am 105:2871-2884

Schultz R, Wang R, Gu YJ, Haug K, Atkinson G (2017) A seismological overview of the induced earthquakes in the Duvernay play near Fox Creek, Alberta. J Geophys Res 122:492-505

Schultz R, Skoumal R, Brudzinski M, Eaton D, Baptie B, Ellsworth W (2020a) Hydraulic fracturing induced seismicity. Rev Geophys 58:e2019RG000695

Schultz R, Beroza G, Ellsworth W, Baker J (2020b) Riskinformed recommendations for managing hydraulic fracturing-induced seismicity via traffic light protocols. Bull Seismol Soc Am 110:2411-2422. https://doi. org/10.1785/0120200016

Shapiro SA, Dinske C, Langenbruch C (2010) Seismogenic index and magnitude probability of earthquakes induced during reservoir fluid stimulations. Lead Edge 29:304-309 
Skoumal RJ, Brudzinski MR, Currie BS (2015) Earthquakes induced by hydraulic fracturing in Poland Township, Ohio. Bull Seismol Soc Am 105:189-197

Skoumal RJ, Brudzinski MR, Currie BS (2018a) Proximity of Precambrian basement affects the likelihood of induced seismicity in the Appalachian, Illinois, and Williston basins, central and eastern United States. Geosphere 14:1365-1379

Skoumal RJ, Ries R, Brudzinski MR, Barbour AJ, Currie BS (2018b) Earthquakes induced by hydraulic fracturing are pervasive in Oklahoma. J. Geophys. Res 123:10918-10935

van der Baan M, Calixto FJ (2017) Human-induced seismicity and large-scale hydrocarbon production in the USA and Canada. Geochem. Geophys. Geosyst 18:2467-2485

van der Elst NJ, Page MT, Weiser DA, Goebel THW, Hosseini SM (2016) Induced earthquake magnitudes are as large as (statistically) expected. J Geophys Res Solid Earth 121: 4575-4590

van Elk J, Bourne SJ, Oates SJ, Bommer JJ, Pinho R, Crowley H (2019) A probabilistic model to evaluate options for mitigating induced seismic risk. Earthquake Spectra 35:537-564

Verdon JP (2014) Significance for secure $\mathrm{CO}_{2}$ storage of earthquakes induced by fluid injection. Environ Res Lett 9: 064022

Verdon JP, Budge J (2018) Examining the capability of statistical models to mitigate induced seismicity during hydraulic fracturing of shale gas reservoirs. Bull Seismol Soc Am 108: 690-701

Verdon JP, Kendall J-M, Horleston AC, Stork AL (2016) Subsurface fluid injection and induced seismicity in southeast Saskatchewan. Int. J. Greenh. Gas Control 54:429-440

Verdon JP, Kendall J-M, Hicks SP, Hill P (2017) Using beamforming to maximise the detection capability of seismometer arrays deployed to monitor oilfield activities. Geophys Prospect 65:1582-1596

Verdon, J.P., N. Igonin, J-M. Kendall, D.W. Eaton, 2019. Fault reactivation via pre-existing fracture networks during hydraulic fracturing. Society of Earthquake and Civil Engineering Dynamics Conference, Greenwich London, Conference Proceedings 7.4

Vilarrasa V, Carrera J (2015) Geologic carbon storage is unlikely to trigger large earthquakes and reactivate faults through which $\mathrm{CO}_{2}$ could leak. Proc Natl Acad Sci 112:5938-5943
Wang R, Gu YJ, Schultz R, Kim A, Atkinson G (2016) Source analysis of a potential hydraulic-fracturinginduced earthquake near Fox Creek. Geophys. Res. Lett 43:564-573

Westaway R, Younger PL (2014) Quantification of potential macroseismic effects of the induced seismicity that might result from hydraulic fracturing for shale gas exploitation in the UK. Q J Eng Geol Hydrogeol 47:333-350

Woessner J, Laurentiu D, Giardini D, Crowley H, Cotton F, Grünthal G, Valensise G, Arvidsson R, Basili R, Demircioglu MB, Hiemer S, Meletti C, Musson RW, Rovida AN, Sesetyan K, Stucchi M, The SHARE Consortium (2015) The 2013 European Seismic Hazard Model: key components and results. Bull Earthq Eng 13: 3553-3596

Yeck WL, Hayes GP, McNamara DE, Rubinstein JL, Barnhart WD, Earle PS, Benz HM (2017) Oklahoma experiences largest earthquake during ongoing regional wastewater injection hazard mitigation efforts. Geophys Res Lett 44:711-717

Yi G, Long F, Liang M, Zhao M, Wang S, Gong Y (2019) Focal mechanism solutions and seismogenic structure of the 17 June 2019 M 6.0 Sichuan Changning earthquake sequence: Chinese. J Geophys 62:3432-3447

Yoon CE, Huang Y, Ellsworth WL, Beroza GC (2017) Seismicity during the initial stages of the Guy-Greenbrier, Arkansas, earthquake sequence. J Geophys Res 122:9253-9274

Zoback MD (2012) Managing the seismic risk posed by waste water disposal. EARTH Magazine 57:38

Zoback MD, Townend J, Grollimund B (2002) Steady-state failure equilibrium and deformation of intraplate lithosphere. Int Geol Rev 44:383-401

Zöller G, Holschneider M (2016) The maximum possible and the maximum expected earthquake magnitude for productioninduced earthquakes at the gas field in Groningen, the Netherlands. Bull Seismol Soc Am 106:2917-2921

Publisher's note Springer Nature remains neutral with regard to jurisdictional claims in published maps and institutional affiliations. 